\title{
Revealing their innermost secrets: an evolutionary perspective on the disparity of the organ systems in anomuran crabs (Crustacea: Decapoda: Anomura)
}

\author{
Jonas Keiler ${ }^{1,2}$, Stefan Richter ${ }^{1}$, Christian S. Wirkner ${ }^{1}$ \\ ${ }^{1}$ Allgemeine \& Spezielle Zoologie, Universitaet Rostock, Universitaetsplatz 2, 18055 Rostock, Germany \\ ${ }^{2}$ E-mail: jonas.keiler@gmx.de
}

Key words: Aegla, Anomala, carcinization, evolutionary morphology, hemolymph vascular system, Kiwa, Lomis, nervous system

\begin{abstract}
The Southern Australian crustacean species Lomis hirta (Lomisoidea: Lomisidae) is a representative of one of the three anomuran taxa which obtained their crab-like habitus independently from each other. This process, the evolutionary transformation into a crab-like form, is termed carcinization. To shed light on the morphological changes which took place during carcinization and to investigate structural dependence (coherence) between external and internal morphological characters, we studied $L$. hirta and representatives of its putatively most closely related taxa, Aegla cholchol (Aegloidea: Aeglidae) and Kiwa puravida (Chirostyloidea: Kiwaidae). External and internal anatomy was studied using microcomputertomography and computer-aided 3D reconstruction. A. cholchol and K. puravida belong to equally exceptional lineages: Aegla is endemic to South America and lives in freshwater habitats; Kiwa is a deep sea dweller associated to chemosynthetic bacteria found in methane seeps or hydrothermal vents. On the basis of recent cladistic analyses we reconstruct the anatomical ground pattern of the squat lobster-like last common ancestor of the three taxa and trace the morphological transformations that affected inner and outer morphology in the recent forms. Our results show, among other things, that the pleon in Lomis underwent drastic modifications in the context of carcinization, including a reduction of the muscular portion leaving more room for the hepatopancreas and gonads, and a narrowing of the pleonal ganglia which became shifted anteriorly into the cephalothorax and attached to the cephalothoracic ganglion. We interpret these anatomical changes in Lomis to have come about because of the loss of the caridoid escape reaction, which in turn was a direct consequence of the evolution of a strongly bent pleon as part of the crab-like habitus, and of a hidden lifestyle.
\end{abstract}

\section{Contents}

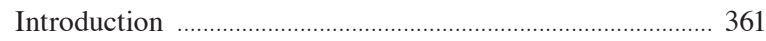

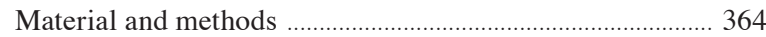

Studied species ……......................................................... 364

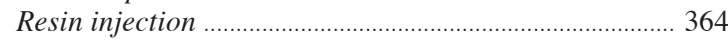

Fixation and dehydration ............................................... 365

Microcomputer tomography (MicroCT) .......................... 365

$3 D$ reconstruction …………............................................. 365

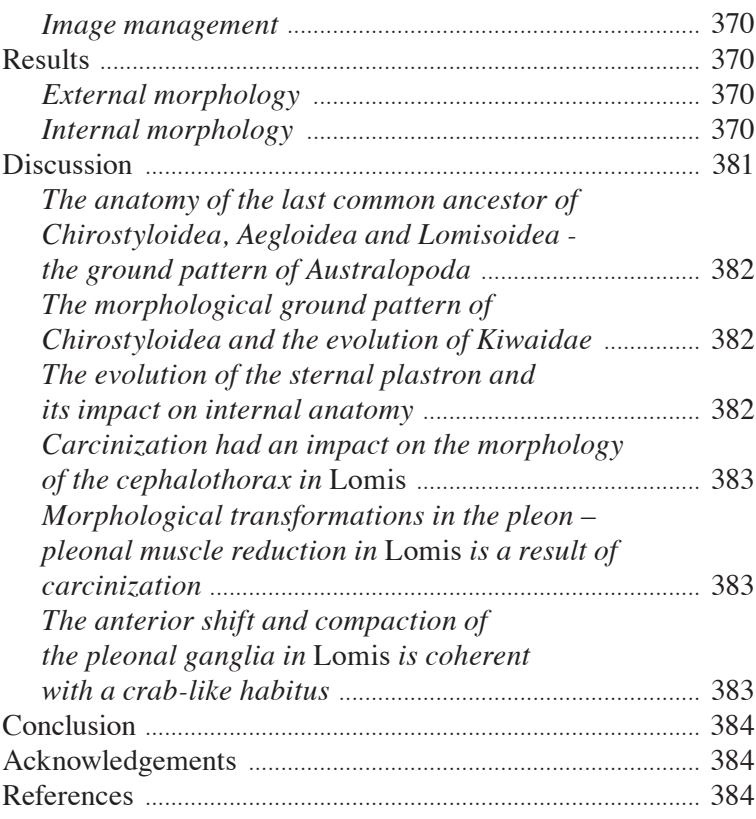

\section{Introduction}

Anomura (or Anomala) is the taxon with the greatest disparity within Decapoda when the number of different body shapes - crabs, squat lobsters, symmetrical and asymmetrical hermit crabs and mole crabs (Tsang et al., 2011) - is taken into account. Apart from mole crabs, none of these groups is likely to be monophyletic. The crab-like body shape alone evolved three times independently within anomurans, and independently from the crab-like body shape in brachyurans (Fig. 1; see also Reimann et al., 2011). The term carcinization was introduced a century ago to describe the evolutionary process which led to a crab-like habitus (Borradaile, 1916; McLaughlin, 1983; McLaughlin and Lemaitre, 1997; Scholtz, 2014), though the phenomenon itself 


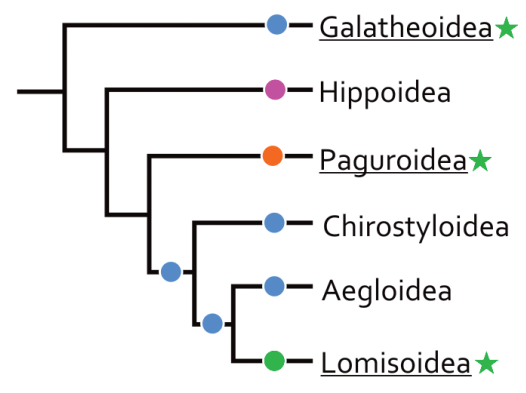

(Schnabel et al., 2011)

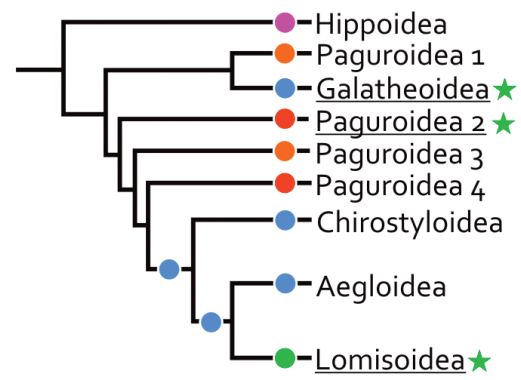

(Tsang et al., 2011)

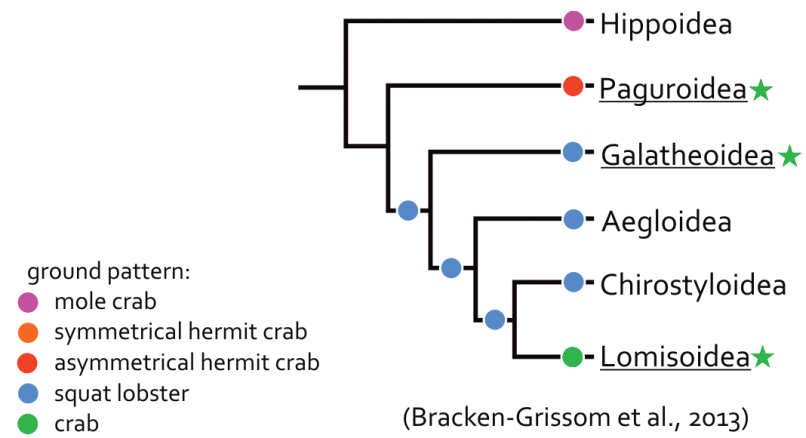

Fig. 1. Different phylogenies of Anomura based on molecular + morphological (Schnabel et al., 2011) and solely molecular data (Tsang et al., 2011 and BrackenGrissom et al., 2013) implying that Lomisoidea evolved from a squat lobster-like ancestor. Coloured dots indicate body shape in the ground pattern in the respective taxon. Underlined taxa included crablike forms.

began to be investigated even earlier (e.g. Boas 1880a, b; Bouvier 1895). Consistently with the disparity found in the external morphology of anomurans, comprehensive studies into the internal anatomy of various anomuran taxa have revealed a variety of differently constituted inner anatomical structures (Jackson, 1913; Pike, 1947; MacGaw and Duff, 2008; Keiler et al., 2013, 2015a, b). Some of these inner structures appear to be phylogenetically informative, e.g. provide evidence of sister group relationships (Keiler et al., 2013, 2015a, b), and at the same time shed light on the morphological transformations which took place in the course of carcinization. Studies into king crabs (Keiler et al., 2013, 2015b) and porcelain crabs (Keiler et al., 2015a) have shown that carcinization in these two lineages was characterized by similar changes in external morphology, e.g. the pleon became flexed and started to be carried tightly under the cephalothorax, which led to the concave emargination of the posterior margin of the sternal plastron and the broadening of the carapace. Some internal organs, especially those of the nervous system and the hemolymph vascular system, were also affected by carcinization in similar ways in the different taxa. In other respects, however, these and other organs evolved differently, reflecting the convergent evolution of a crab-like habitus (Keiler et al., 2013; 2015a, b).
To extend the insights into carcinization obtained by previous investigations, we studied Lomis hirta (Lomisoidea: Lomisidae) as the third and final taxon in our survey of crab-like anomurans. Lomis hirta is endemic to the intertidal of southern Australia and northern Tasmania (Poore, 2004) and the only representative of the monotypic Lomisoidea. For comparison, Aegla cholchol (Aegloidea: Aeglidae) and Kiwa puravida (Chirostyloidea: Kiwaidae), each belonging to similarly exceptional lineages within anomuran crustaceans, were also studied. Aegloidea is represented by a single genus, Aegla, whose representatives are endemic to South America and - despite a single hermit crab species (McLaughlin and Murray, 1990) a unique feature among anomuran crustaceans - live in freshwater (McLaughlin et al., 2010). Representatives of Kiwa, also known as 'yeti crabs', live chemosyntheticassociated at deep sea methane seeps or hydrothermal vents (Thurber et al., 2011; Roterman et al., 2013). While Lomis has a crab-like habitus, Aegla and Kiwa each resemble squat lobsters (Tsang et al., 2011) in having a carapace longer than it is broad and a pleon which is only partly flexed under the cephalothorax. The phylogenetic position of Lomis has been under discussion since the taxon was first described by Lamarck (1818) as an alleged representative of porcelain crabs. In his revision, Milne Edwards (1837) 
placed Lomis closer to lithodid king crabs; Stimpson (1858), in turn, closer to hapalogastrid king crabs. Later, Bouvier (1895) suggested a closer relationship to the hermit crabs Mixtopagurus (Pylochelidae) and Paguristes (Diogenidae). Subsequent authors, more or less following Bouvier, placed Lomis close to symmetrical hermit crabs (Boas, 1926; Balss, 1957; Pilgrim, 1965) or as sister group to the Paguroidea (hermit crabs + king crabs) (Richter and Scholtz, 1994; Reimann et al., 2011). In the morphology-based cladistic analysis by Martin and Abele (1986), Lomis and king crabs clustered together and formed the sister group to hermit crabs. McLaughlin (1983), who revised the external morphology of Lomis, called it a 'highly [...] specialized taxon' representing a 'distinct evolutionary lineage' within Anomura. She denied that it was especially close to paguroids and placed Lomis in its own superfamily taxon without phylogenetic affinities. More recent studies, however, point to a closer relationship between Lomis and Aegla (Morrison et al., 2002; Tudge and Scheltinga, 2002; Schnabel et al, 2011; Tsang et al., 2011; Keiler and Richter, 2011; Bracken-Grissom et al.,2013), which are either sister groups or cluster in a clade together with Chirostyloidea (Bracken-Grissom et al., 2013; but see also Reimann et al., 2011). Aegla - which shares the squat lobster habitus - was traditionally classified as belonging to Galatheoidea (Henderson, 1888 (as Galatheidea); Ortmann, 1892 (as Galatheidea); Balss, 1957; Martin and Abele, 1986; Martin and Davis, 2001). In more recent analyses, the non-monophyly of the traditional Galatheoidea has been recognized and Aegla and the newly discovered squat lobster-like Kiwa species (MacPherson et al. 2005; Thurber et al. 2011) were excluded from Galatheoidea and each transferred to their own superfamily taxon (McLaughlin et al., 2007; DeGrave et al., 2009). Recently, Chirostylidae was also excluded from the remaining Galatheoidea and is now combined with Kiwa in the newly erected taxon Chirostyloidea (Schnabel et al, 2011; Bracken-Grissom et al., 2013). According to recent cladistic analyses (Fig. 1), Lomis is either a sister group to Aegla with Chirostyloidea basal to this clade (Schnabel et al., 2011; Tsang et al., 2011), or sister group to Chirostyloidea with Aegla basal to this clade (Bracken-Grissom et al., 2013). The sister group relationship between Aegla and Lomis is additionally supported by morphological data (Tudge and Scheltinga, 2002; Keiler and Richter, 2011). The clade formed by Aegloidea, Lomisoidea and Chirostyloidea is herein termed Australopoda (tax. nov.). On the basis of this evidence, the most probable scenario appears to be the derivation of Lomis from a squat lobster-like ancestor representing the Australopoda ground pattern. The crab-like habitus of Lomis is thus the derived condition, while a squat lobster habitus can be regarded as plesiomorphic within Australopoda (Tsang et al., 2011). Using micro-computer tomography and computeraided $3 \mathrm{D}$ reconstruction, we studied and compared the anatomy of L. hirta, A. puravida, and K. puravida in order to reconstruct the anatomical ground pattern of Australopoda and, starting from the ground pattern of Australopoda, to reconstruct the morphological transformations which, within the context of carcinization, led to the hairy stone crab L. hirta. Our findings are compared herein with anatomical descriptions and evolutionary interpretations of other instances of carcinization within Anomura.

\section{Material and methods}

\section{Studied species}

The following species were studied:

Lomisoidea Bouvier, 1895

Lomisidae Bouvier, 1895

Lomis hirta (Lamarck, 1818) (North coast of Tasmania near Penguin: 416'1.469' S, 146³'23.711'” W)

Aegloidea Dana, 1852

Aeglidae Dana, 1852

Aegla cholchol Jara \& Palacios, 1999 (Cholchol river, Chile: 38³6'5.56”' S, 7252’25.36” W)

Chirostyloidea Ortmann, 1892

Kiwaidae MacPherson, Jones \& Segonzac, 2005

Kiwa puravida Thurber, Jones \& Schnabel 2011 (deep sea off Costa Rica: $8^{\circ} 55.8^{\prime}$ N 84 $18.8^{\prime}$ W)

A full list of the studied specimens (which are catalogued and stored in the Zoological Collection of the University of Rostock) and a description of each of the methods used are provided in Supporting Information Table S1.

\section{Resin injection}

The acrylic casting resin Mercox 2-CL (Ladd Research, Williston, VT) or the polyurethane-based casting resin PU4ii (vasQtec, Zurich, Switzerland) was injected into the heart of defrosted specimens (K. puravida) or specimens previously killed using $\mathrm{CO}_{2}$-saturated water (A. cholchol) or water mixed with $1 \mathrm{~g} / 100$ $\mathrm{mL}$ clove powder (L. hirta). In a first step, PU4ii was 
Table 1. Conditions of selected anatomical features in Aegla cholchol, Kiwa puravida, Lomis hirta and their last common ancestor (ground pattern of Australopoda). Correspondences are highlighted in the same colour.

\begin{tabular}{|c|c|c|c|c|}
\hline \multicolumn{2}{|l|}{ Ground pattern of Australopoda } & \multirow{2}{*}{$\begin{array}{l}\text { A. cholchol } \\
\text { left (11), right (1) }\end{array}$} & \multirow{2}{*}{$\begin{array}{l}K . \text { puravida } \\
\text { left (2) }\end{array}$} & \multirow{2}{*}{$\begin{array}{l}\text { L. hirta } \\
\text { left (11) }\end{array}$} \\
\hline course descending artery & left & & & \\
\hline $\begin{array}{l}\text { merging point desc. artery - } \\
\text { ventral vessel }\end{array}$ & $\mathrm{p} 3 \mathrm{a}$ & $\mathrm{p} 3 \mathrm{a}$ & $\mathrm{p} 3 \mathrm{a}$ & p2a-p3a \\
\hline anterior ceca & 2 short tubes & 2 vestigal lobes & 2 short tubes & 2 short tubes \\
\hline posterior cecum & present & 1-2 pl. segm. & absent & 5.pl. segm. \\
\hline antennal bladder & lobed & tubular & lobed & lobed \\
\hline posterior margin of plastron & straight & straight & triangular emargination & triangular emargination \\
\hline $3^{\text {rd }}$ thoracic sternite & confluent with plastron & confluent with plastron & confluent with plastron & bent dorsally \\
\hline plastron & completely uncovered & completely uncovered & completely uncovered & partly covered \\
\hline body length : width (in vivo) & $1.7-1.8$ & 1.8 & 1.7 & 1.3 \\
\hline carapace length : width & $1.0-1.1$ & 1.1 & 1.0 & 0.8 \\
\hline dorsally visible pleon segments & $1-4$ & $1-4$ & $1-2$ & $1-2$ \\
\hline anterior gastric muscle artery & with rostral artery & separate & with rostral artery & with rostral artery \\
\hline fifth leg artery (p5a) & separate & root with p4 artery & separate & separate \\
\hline pleonal ganglia & separate (regular) & separate (irregular) & separate (regular) & fused \\
\hline thoracic bridge & two (ep 4/5, 5/6) & one (ep 4/5) & one (ep 4/5) & two (ep 4/5, 5/6) \\
\hline eighth dorsal thoracic muscle & short & short & long & short \\
\hline endophragmal lever & short & short & long & short \\
\hline pleonal muscles & pronounced & pronounced & pronounced & reduced \\
\hline gills & phyllobranchiate & trichobranchiate & phyllobranchiate & trichobranchiate \\
\hline thoracopleonal extensor & present & present & present & reduced \\
\hline bifurcation posterior aorta & th8-pl1 & th8-pl1 & pl5-pl6 & pl4 \\
\hline anterior branch ila & below ala & below ala & ascending & below ala \\
\hline $1^{\text {st }}$ maxillipedal arteries & posterior to bifurcation & posterior to bifurcation & posterior to bifurcation & anterior to bifurcation \\
\hline $\begin{array}{l}\text { posterior extension of } \\
\text { hepatopancreas }\end{array}$ & $3^{\text {rd }}$ pleonal segment & $3^{\text {rd }}$ pleonal segment & $2^{\text {nd }}-3^{\text {rd }}$ pleonal segment & fourth pleonal segment \\
\hline $\begin{array}{l}\text { anterior extension of } \\
\text { hepatopancreas }\end{array}$ & anterior margin stomach & anterior margin stomach & rostrum & $\begin{array}{l}\text { anterior margin } \\
\text { stomach }\end{array}$ \\
\hline ovaries & $3^{\text {rd }}$ pleonal segment & $3^{\text {rd }}$ pleonal segment & unknown & $6^{\text {th }}$ pleonal segment \\
\hline
\end{tabular}

mixed with an x-ray opaque additive (sublimated iodine or Tetric EvoFlow ${ }^{\circledR}$ composite (Ivoclar Vivadent, Eilwangen, Germany) dissolved in 2-butanone) while Mercox was used unadulterated (see S1). In a next step, the resin was mixed with the appropriate catalyst and placed in a $5 \mathrm{ml}$ syringe (Luer Lock Solo, Braun, Melsungen, Germany) just before use. The resin in the syringe was injected via an injection cannula (diameter 0.3-0.6 mm, Sterican, Braun, Melsungen, Germany) through the carapace into the heart and the specimens were left for several minutes to allow the resin to polymerize and temper.

\section{Fixation and dehydration}

For MicroCT specimens (injected and non-injected) were fixed in Dubosc's fluid or with saline (30-35 PSU) Bouin's fluid or glutaraldehyde (4\%) for several days, washed, stained with $1 \%$ alcoholic or aqueous iodine, washed and then critical point (EMITECH
K850, UK) or freeze (UniCryo MC2L, UniEquip, Munich, Germany) dried.

\section{Microcomputer tomography (MicroCT)}

Dried specimens were mounted with hot glue on a specimen holder. X-ray imaging was performed with a - Phoenix Nanotom-180 (Phoenixlx-ray, GE Sensing \& Inspection Technologies) high-resolution MicroCT system.

- Xradia MicroXCT-200 X-ray imaging system (Carl Zeiss X-ray Microscopy Inc., Pleasanton, USA).

For detailed parameters and details of the process see Keiler et al. (2015b).

\section{$3 D$ reconstruction}

For all 3D reconstructions, the software Imaris 6.4.1 and 7.0.0 (Bitplane) was used (for details of the process see Keiler et al., 2015a). 

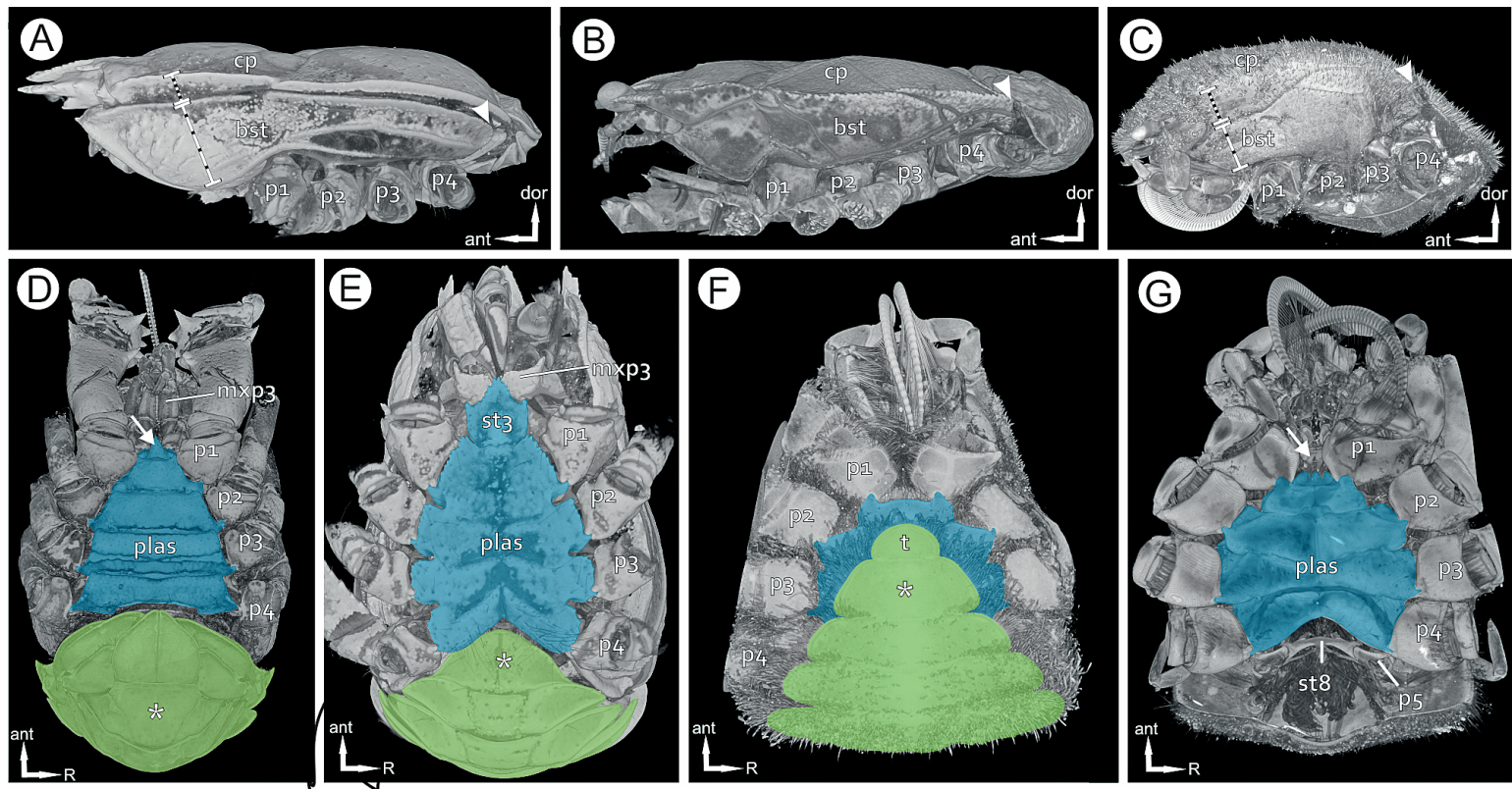

$(\mathbb{H}$
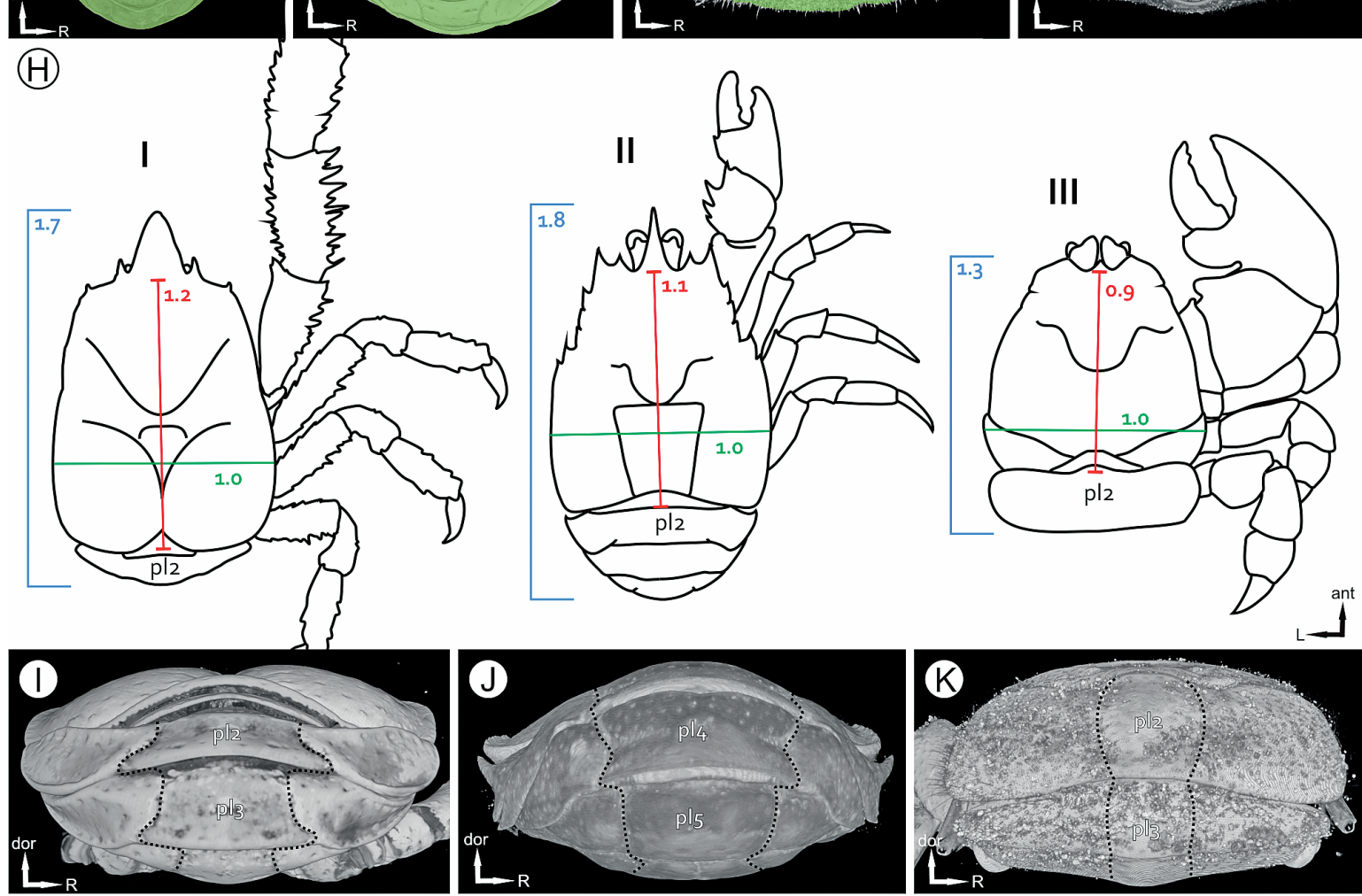

Fig. 2. External integumental structures (volume renderings). A-C. Lateral view of Kiwa puravida (A), Aegla cholchol (B) and Lomis hirta (C). Dashed and dotted lines indicate the different height ratios of the branchiostegites present in K. puravida (A) and $L$. hirta (B). Arrow indicates linea anomurica; arrowhead indicates posterior extension of the lower branchiostegite (lbs). D-G. Ventral view of $A$. cholchol (D), K. puravida (D), L. hirta (F-G; males); pleon virtually cut in G to show plastron (plas). Arrow in G points at the vertically oriented 3rd thoracic sternites. Asterisk indicates $6^{\text {th }}$ pleonal segment. H. Schematic drawings of the various different shaped integumental structures in the studied species: I. K. puravida, II. A. cholchol. III. L. hirta. Pleon in in vivo condition. Red values show the relative ratios of carapace length to width without rostrum (width set to 1.0). Blue values show the relative length of the body (with pleon bent in vivo). Scale varies between drawings. I-K. Posterior view of bent pleon in K. puravida (I), A. cholchol (J), and L. hirta (K). Dotted yellow lines indicate divide between tergites and pleurites. Abbreviations: bst, branchiostegite; p1-p5, pereiopods; pl, pleon; pl1-6, pleonal segments; plas, plastron; st3, 3rd thoracic sternite; st8, 8th thoracic sternite. 


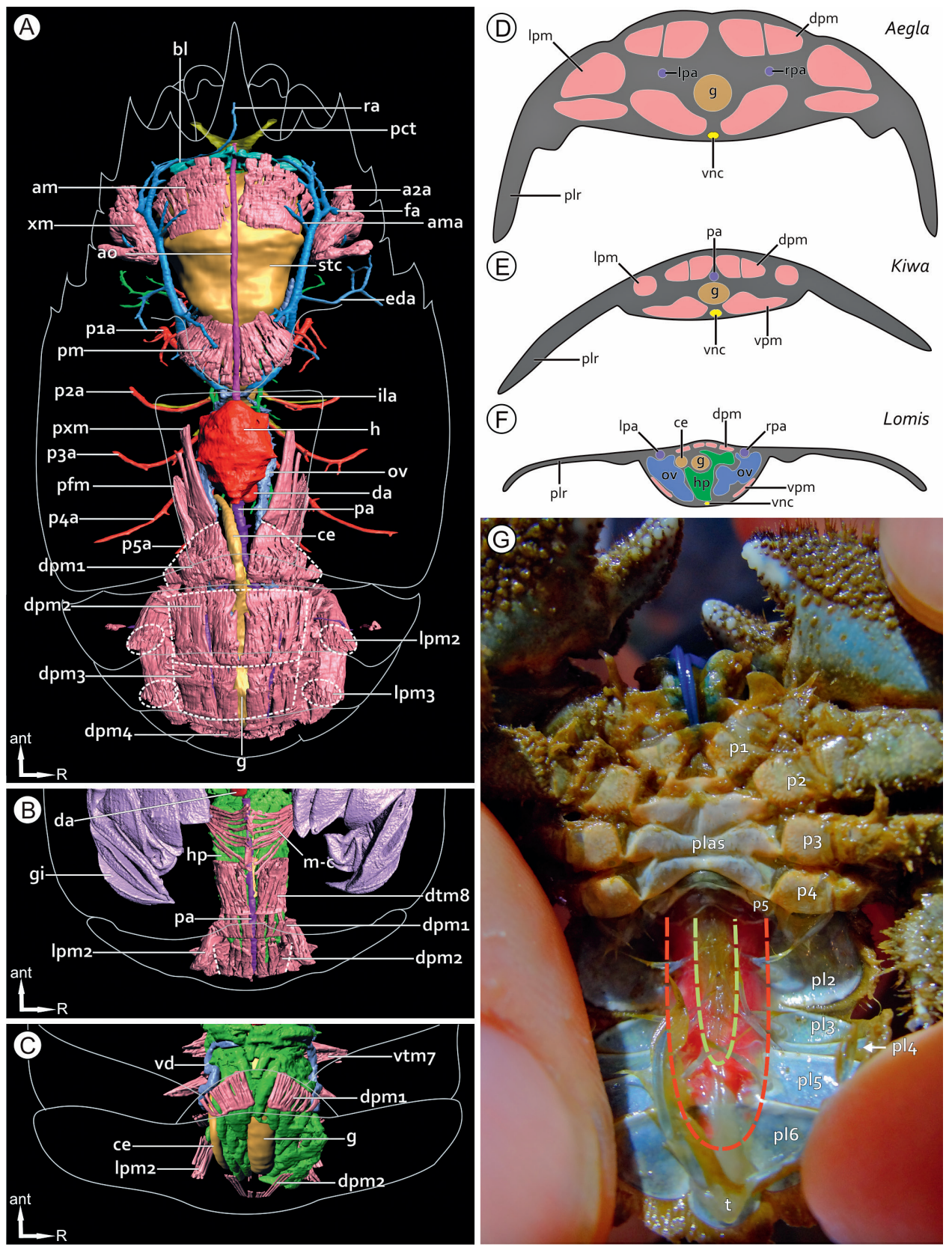

Fig. 3. Muscle systems. A. Dorsal view of the pleonal (dpm+lpm), dorsal gastric (am+pm) and external mandible adductor (xm) muscles in Aegla cholchol and their position within the body. B. Pleonal muscles (dpm+lpm) and dorsal thoracic muscles (dtm) in Kiwa puravida. C. Pleonal muscles (dpm+lpm) in Lomis hirta. D-F. Schematic cross-section through fourth pleonal segment of A. cholchol (D), $K$. puravida $(\mathrm{E})$ and $L$. hirta $(\mathrm{F})$ revealing the differing degree of flexion of the pleurites (plr) and the differing relationships between segmental body and pleurites. Note the relatively small proportion of pleonal muscle in $L$. hirta and the posterior extension of the ovaries (blue dashed line) and hepatopancreas (green dashed line). G. Photograph of the ventral side of L. hirta with the pleon unflexed revealing the posterior extension of the ovaries and the relationship between the narrow pleonal segments and the wide pleurites. Abbreviations: a2a, antennal arteries; am, anterior gastric muscles; ama, anterior gastric muscle artery; ao, anterior aorta; bl, antennal bladder; ce, cecum; da, descending artery; dpm, dorsal pleonal muscles; dtm, dorsal thoracic muscles; eda, epidermal artery; fa, fringe artery; g, gut; gi, gills; hp, hepatopancreas; inferior lateral arteries; lpa, left pleonal artery; lpm, lateral pleonal muscles; ov, ovaries; p1-p4; legs (pereiopods); pla-p4a, leg arteries; pa, posterior aorta; pct, protocerebral tract; pl2-pl6, pleonal segments; plas, plastron; pm, posterior gastric muscles; ra, rostral artery; rpa, right pleonal artery; stc, stomach; t, telson; vd, vas deferens; vpm, ventral pleonal muscles; xm, external mandible adductor muscles. 

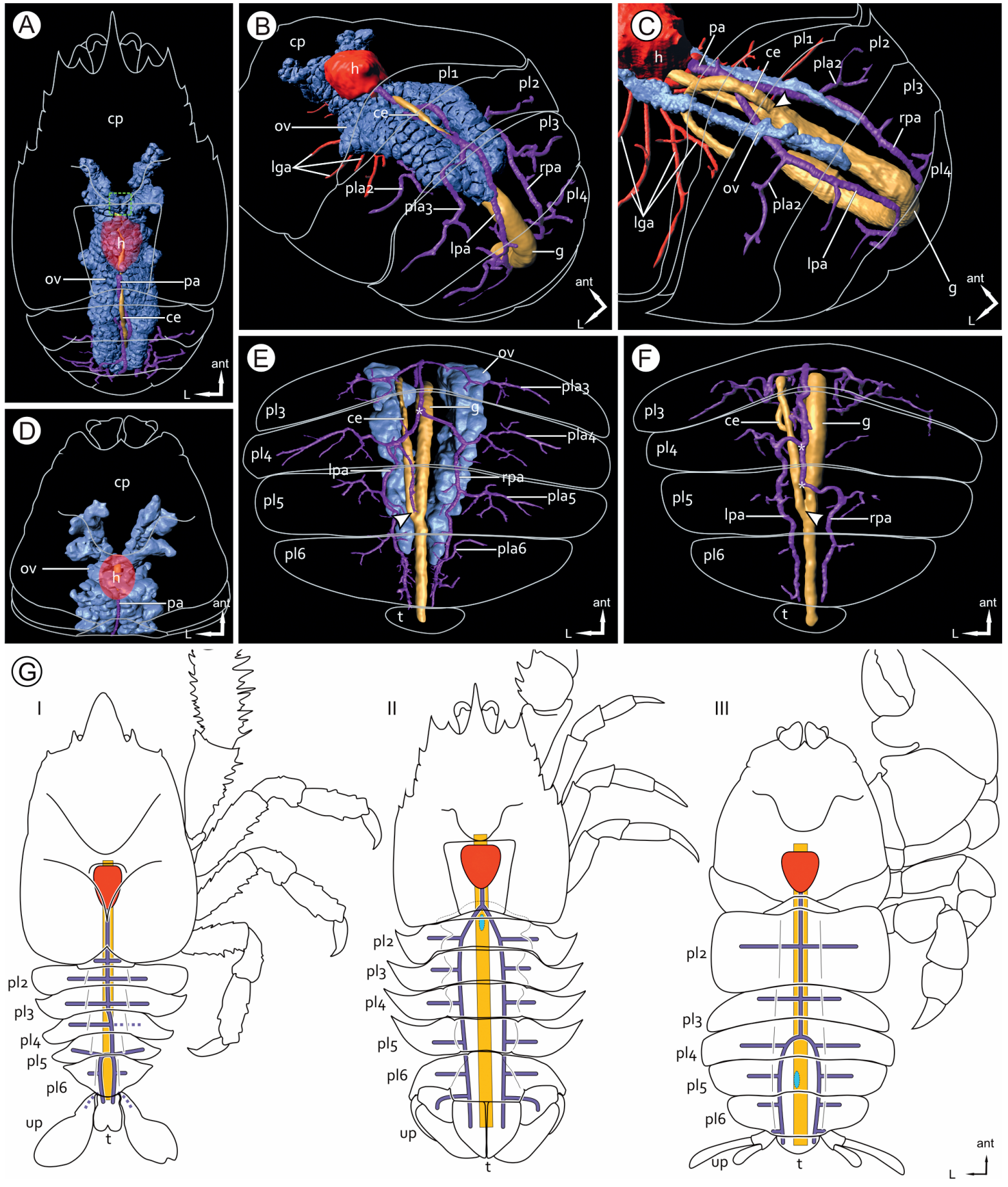

Fig. 4. Spatial relationships between integument, posterior aorta and other internal organs. A-C. Aegla cholchol, females. A. dorsal view. B. Posterodorsolateral view. C. Posterodorsolateal view. Specimen with sparsely filled ovaries reveals spatial proximity between cecum and posterior split of posterior aorta. Arrowhead points at root of posterior cecum. D-F. Lomis hirta, females, dorsal view. Arrowheads in $\mathrm{E}$ and $\mathrm{F}$ indicate root of posterior cecum. Asterisks indicate root of left and right pleonal arteries. Note the asymmetrical arrangement of pleonal arteries in the specimen shown in F. G. Schematic drawings of Kiwa puravida (I), A. cholchol (II) and L. hirta (III) showing position of heart (red), posterior aorta (violet) and gut (beige). Green oval indicates position of posterior cecum. Pleon in each drawing is artificially unbent. Abbreviations: ce, posterior cecum; cp, carapace; g, gut; h, heart; lpa, left pleonal artery; ov, ovaries; p, posterior aorta; p11-pl6, pleonal segments; pla2-pla6, posterior lateral arteries; rpa, right pleonal artery; t, telson; up, uropod. 

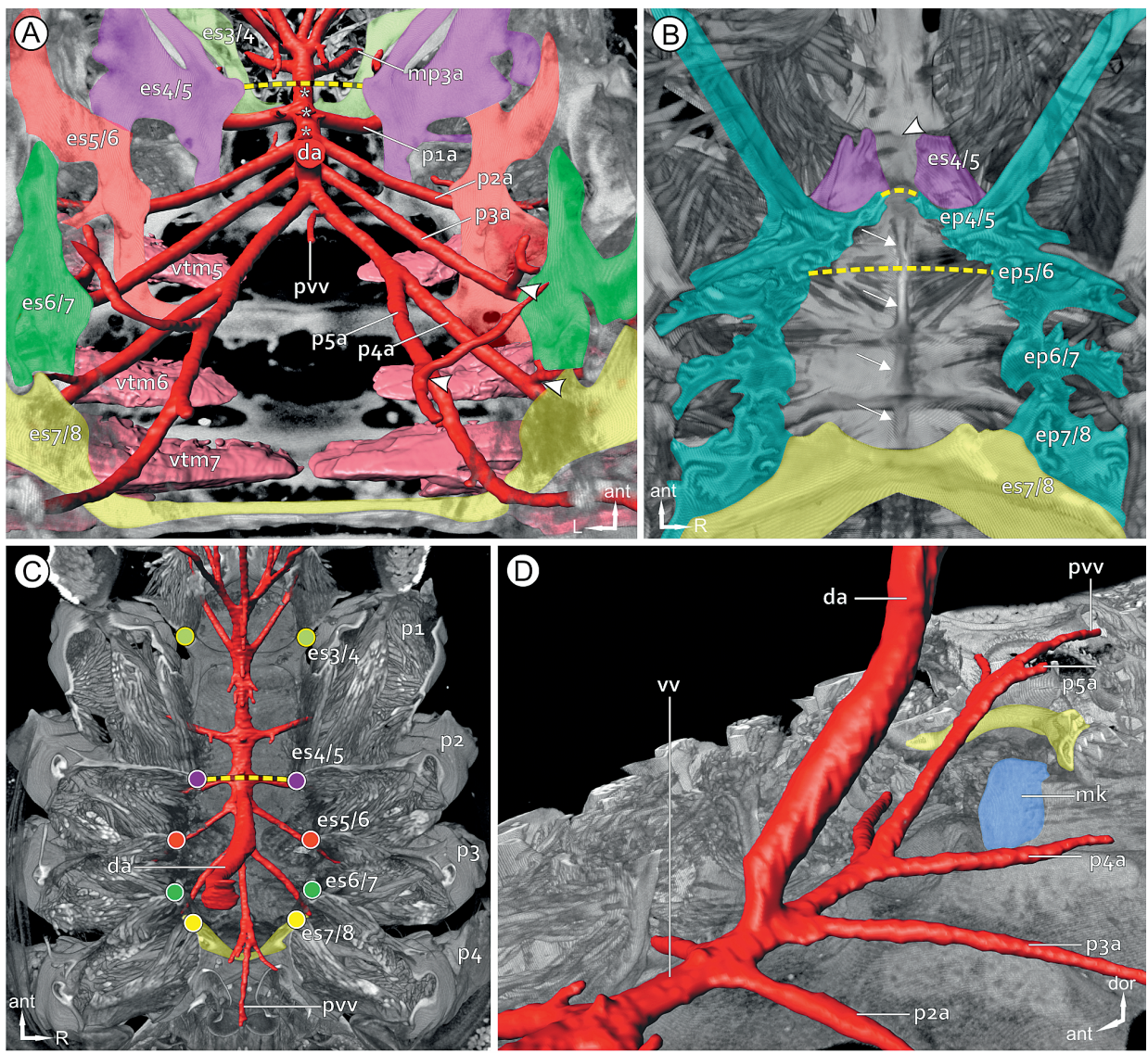

(E)
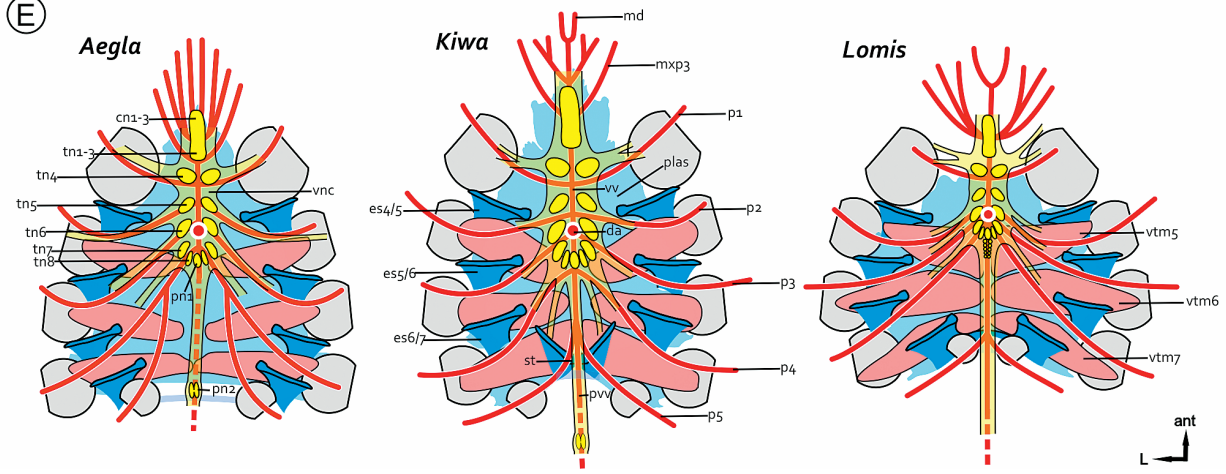

Fig. 5. Spatial relationships between organ systems of the ventral body side. A. Aegla cholchol. Posterodorsal view of virtually opened thoracic region showing coloured endosternites (volume rendering), ventral thoracic muscles (pink; surface rendering) and ventral vessel (red; surface rendering). Arrows point to arteries ascending from the proximal portion of the leg arteries. Asterisks indicate ascending arteries which supply the cephalothoracic ganglion. Dashed yellow line indicates tansverse thoracic bridge. B. Lomis hirta. Posterodorsal view of virtually opened thoracic region (volume rendering). Dashed yellow lines indicate transverse thoracic bridges. Interdigitated endopleurites are shown in cyan. Arrows point to medial ridge of plastron. C. Kiwa puravida. Dorsal view of virtually opened cephalothorax (grey; volume rendering) revealing position of ventral vessel system (red; surface rendering). Medial margins of endosternites are indicated by coloured circles. Dashed yellow line indicates transverse thoracic bridge. D. K. puravida. Anterolateral view of virtually opened thoracic region. The posterior margin of the plastron (yellow) is elevated and partly covers an endophragmal medial keel (blue). Asterisks indicate ascending arteries which supply the cephalothoracic ganglion. E. Schematic drawings of the ventral organs. Colour code: pink, ventral thoracic muscles; light blue, sterna plastron; dark blue, endosternites; red, ventral vessel system; yellow, neuropil areas of the ventral nerve cord. Abbreviations: da, descending arery; es, endosternites; ep, endopleurites; p1-p4, legs (pereiopods); pla-p5a, leg arteries; mk, medial keel; pl, pleon; pvv, posterior ventral vessel; vtm, ventral thoracic muscles; vv, ventral vessel. 


\section{Image management}

All figure plates were arranged using Corel Graphics Suite X3 (Corel, Ottawa). Bitmap images were embedded into Corel Draw X3 files and digitally edited with Corel PhotoPaint X3.

\section{Results}

Both external and internal morphology differs in several regards between Aegla cholchol, Kiwa puravida and Lomis hirta. Notable differences between differently sized specimens of the same species were not found. By studying the anatomical structures in more than one specimen of each species we tried to take possible intraspecific variability into account which, if present, is mentioned. A short summary of anatomical features for each studied species is provided in Table 1.

\section{External morphology}

Kiwa puravida (Fig. 2H I) and Aegla cholchol (Fig. 2H II) possess a carapace slightly longer than it is broad, while Lomis hirta (Fig. 2H III) possesses a more rounded carapace which is slightly broader than it is long (proportions illustrated in Fig. $2 \mathrm{H}$ ). Overall, the dorsal aspect of the body in all three taxa is fairly oval since the pleon is bent under the cephalothorax (Fig. 2D-F), though not to the same degree: in A. cholchol (Fig. 2H II), the first to fourth pleonal segments are visible, while in $K$. puravida (Fig. $2 \mathrm{H} \mathrm{I}$ ) and L. hirta (Fig. 2H III), only the first and second pleonal segments are visible. The pleurotergites in L. hirta (Fig. $3 \mathrm{~F}$ ) are less convexly bent than in $K$. puravida (Fig. 3E) and A. cholchol (Fig. 3D) and the second pleonal segment in L. hirta is markedly longer than the subsequent ones (Fig. 4G). In K. puravida and A. cholchol, the third to seventh thoracic sternites are confluent to form a sternal plate, or plastron (Fig. 2D-G). In L. hir$t a$, the plastron is formed by the fourth to seventh thoracic sternites, while the third thoracic sternites (arrow, Fig. 2G) are set off from the plastron and dorsally bent. The eighth thoracic sternites in all three species are distinctly separate from the plastron (Fig. 5E). In A. cholchol (Fig. 2D), the plastron has an almost straight posterior margin, while that in K. puravida (Fig. 2E) and L. hirta (Fig. 2G) displays a markedly triangular emargination. In L. hirta, the plastron is partly (male; Fig. 2F) or completely (female; Suppl.Fig. S2) covered by the bent pleon, while it remains uncovered in K. puravida (Fig. 2E) and A. cholchol (Fig. 2D).

\section{Internal morphology}

Digestive system. In all studied species the stomach (stc; gastric mill + pylorus) is situated dorsally in the anterior portion of the cephalothorax. From the posterior end of the pylorus, the gut ( $\mathrm{g}$ ) extends as a tube to the telson (Figs. 6-8). Several muscles insert on the gastric ossicles (go; Fig. 8B); the most prominent being the dorsally located anterior (am) and posterior gastric muscles (pm; Figs. 3A, 7A, 8A, 9), each suspended between stomach and carapace. A pair of short anterior ceca (ce) emanates dorsally from the transition between pylorus and gut (Suppl.-Fig. S3), appearing as short tubes in K. puravida (Fig. 7C, Suppl.-Fig. S3A, B) and L. hirta (Suppl.-Fig. S3C, D) and as smaller lobes in A. cholchol (Suppl.-Fig. S3E, F). An unpaired posterior cecum emanates from the gut in A. cholchol (first pleonal segment, dorsally; Fig. 6A, C) and $L$. hirta (fifth pleonal segment, left-laterally; Fig. 8A, C), but is absent in K. puravida. In L. hirta, the posterior cecum runs anteriorly along the gut before coiling slightly at its end in the second pleonal segment (Fig. 8C). In all studied species, the hepatopancreas (hp) fills most of the cephalothorax and parts of the pleon (Figs. 7A, B, 8B) and is formed by two bunches of tubular diverticles which are each connected to the pylorus via a main duct. The stomach is embedded ventrally by the hepatopancreas, which extends ventrally between the leg nerves of the ventral nerve cord (Figs. 7B, 8D). In K. puravida (Fig. 7B) and A. cholchol, the hepatopancreatic diverticles extend below the ventral vessel. The anterior and posterior extension of the hepatopancreas differs between the taxa: in K. puravi$d a$ (Fig. 7A), the anterior diverticles reach into the rostrum, while in A. cholchol and L. hirta (Fig. 8B) they do not extend past the anterior margin of the stomach. In $K$. puravida, the posterior diverticles extend between the second and third pleonal segment, in $A$. cholchol into the third and in L. hirta (Fig. 3G) into the fourth.

Antennal glands. In all studied species, the antennal glands (ag) are located anterolaterally in the cephalothorax, near the second antennae. Flattened in $K$. puravida (Fig. 7B, Suppl.-Fig. S4E, F), they exhibit a more complex branching pattern in A. cholchol (Suppl.-Figs. S4A, B, S5A) and L. hirta (Suppl.-Fig. S4C, D). In $K$. puravida (Fig. 7A) and L. hirta (Fig. $8 \mathrm{E})$, the lobes of the antennal bladder (bl) are situated 

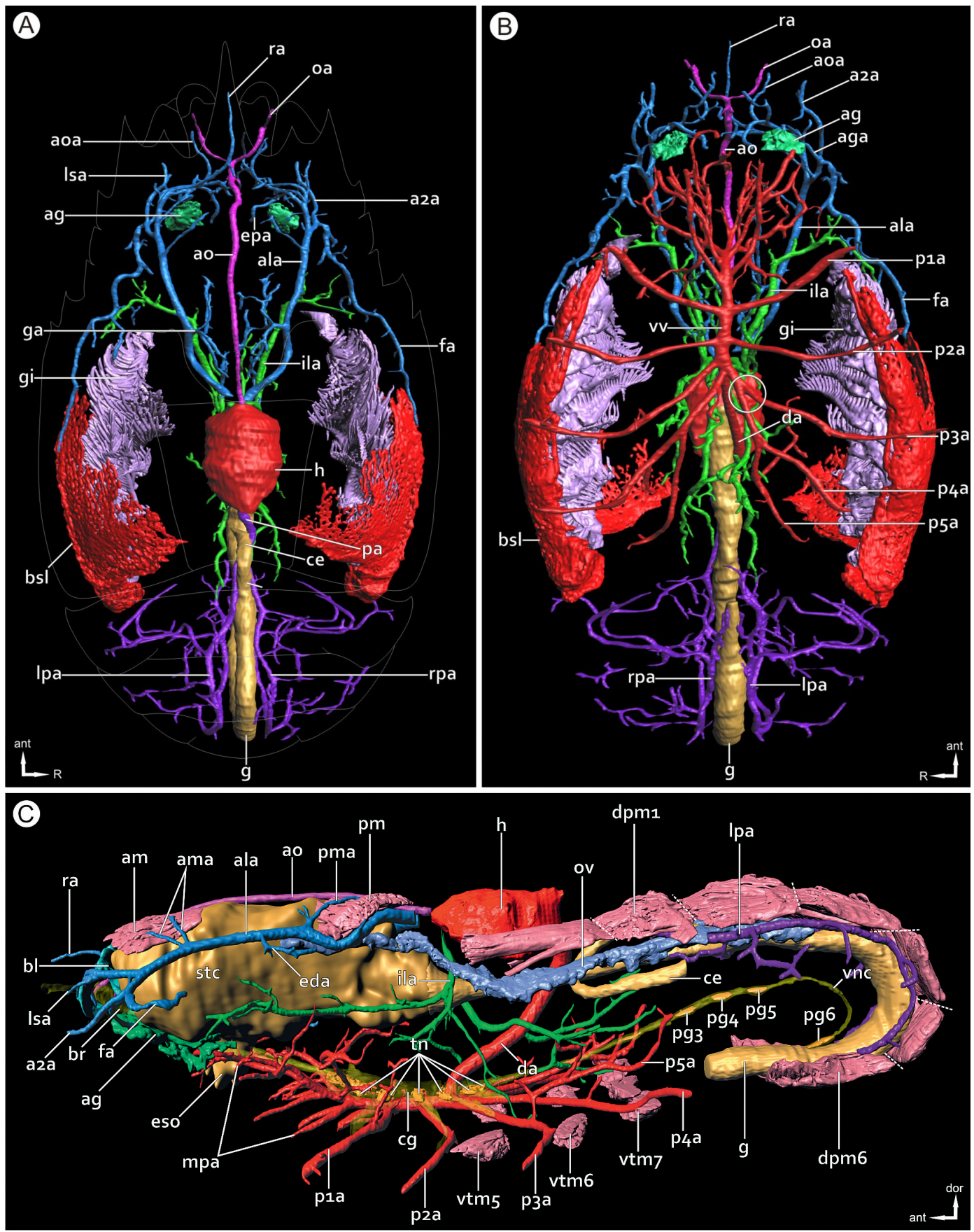

Fig. 6. Spatial relationships between the hemolymph vascular system and other internal organs in Aegla cholchol (surface renderings). PDF version contains interactive 3D content. To activate click on figures A and B in Adobe Reader. Rotate objects with mouse and see further functionalities in content menu. A. Dorsal view. B. Ventral view. Circle indicates common branch of leg arteries p3a-p5a. C. Left-sided lateral view. Abbreviations: a2a, antennal artery; ag, antennal gland; ala, anterior lateral artery; am, anterior gastric muscle; ama, anterior gastric muscle artery; ao, anterior aorta; aoa, accessory optic artery; br, brain; bsl, branchiostegal lacunae; ce, cecum; cg, cephalothoracic ganglion; cp, carapace; da, descending artery; dpm1-6, dorsal pleonal muscles; eda, epidermal artery; epa, epistomal artery; eso, esophagus; fa, fringe artery; g, gut; ga, gastric artery; h, heart; inferior lateral arteries; lpa, left pleonal artery; lsa, lateral spine artery; mpa, mouthpart arteries; ov, ovaries; pla-p5a, leg arteries; pa, posterior aorta; pg3-6, pleonal ganglia; pm, posterior gastric muscle; ra, rostral artery; rpa, right pleonal artery; stc, stomach; tn, thoracic neuropils; vtm5-7, ventral thoracic muscles; vv, ventral vessel; xm, external mandible adductor muscle. 

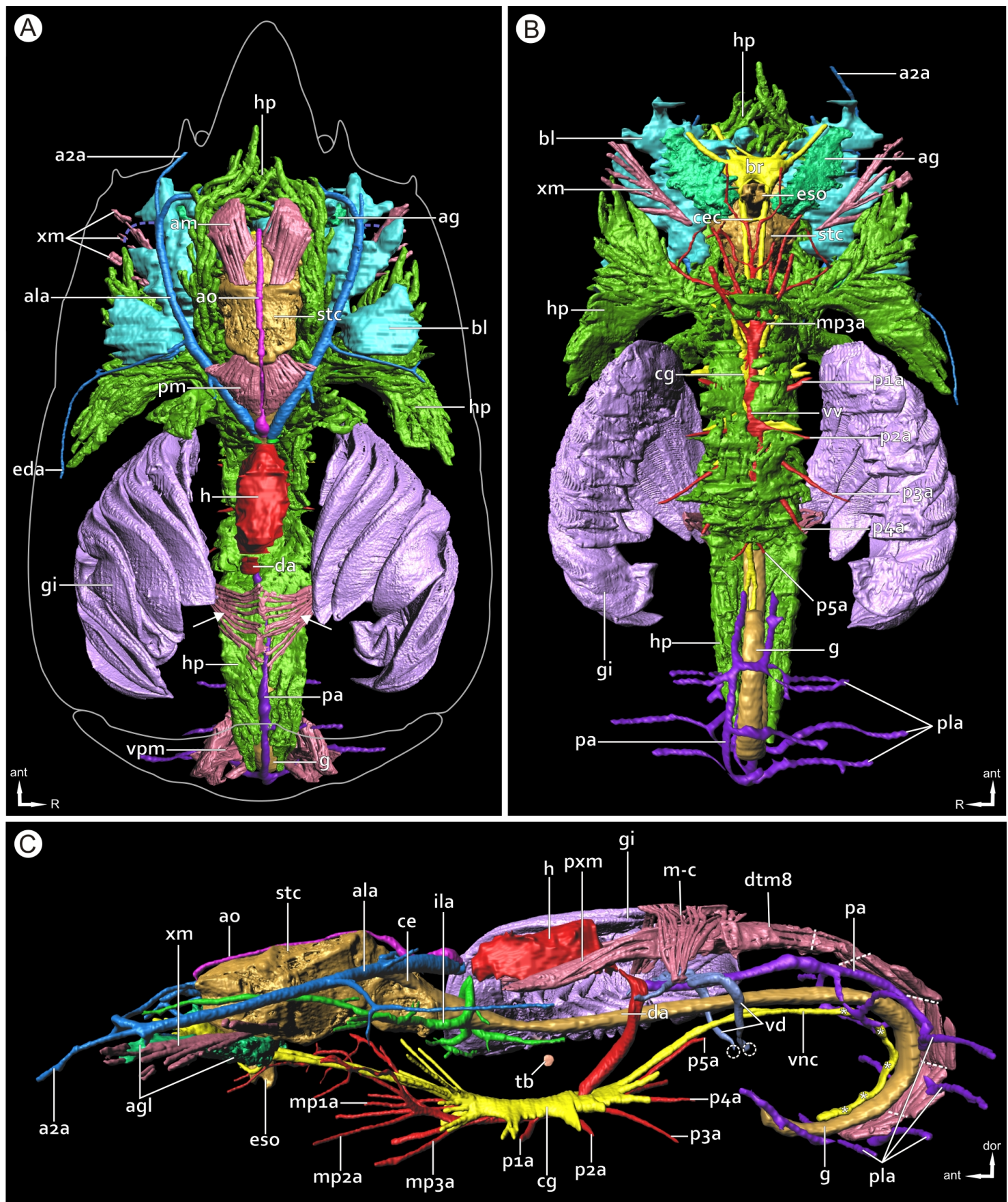

Fig. 7. Spatial relationships between the hemolymph vascular system and other internal organs (surface renderings) in Kiwa puravida. PDF version contains interactive 3D content. To activate click on figure in Adobe Reader. Rotate objects with mouse and see further functionalities in content menu. A. Dorsal view. B. Ventral view. C. Left-sided lateral view. Arrows in A and C point at the dorsal muscles between heart and pleon. Asterisks in $\mathrm{C}$ indicate pleonal ganglia. Abbreviations: a2a, antennal artery; ag, antennal gland; ala, anterior lateral artery; am, anterior gastric muscle; ao, anterior aorta; br, brain; ce, anterior cecum; cec, circumesophageal commissure; cg, cephalothoracic ganglion; da, descending artery; dtm8, dorsal thoracic muscles; eda, epidermal artery; eso, esophagus; g, gut; ga, gastric artery; gi, gills; h, heart; hp, hepatopancreas; inferior lateral arteries; m-c, dorso-lateral thoracic muscles; mpla-mp3a, maxillipedal arteries; pla-p5a, leg arteries; pa, posterior aorta; pg3-6, pleonal ganglia; pla, posterior lateral artery; pm, posterior gastric muscle; pxm, thoracopleonal extensor muscles; stc, stomach; tb, endophragmal thoracic bridge; vnc, ventral nerve cord; vv, ventral vessel; xm, external mandible adductor muscle. 
(A)

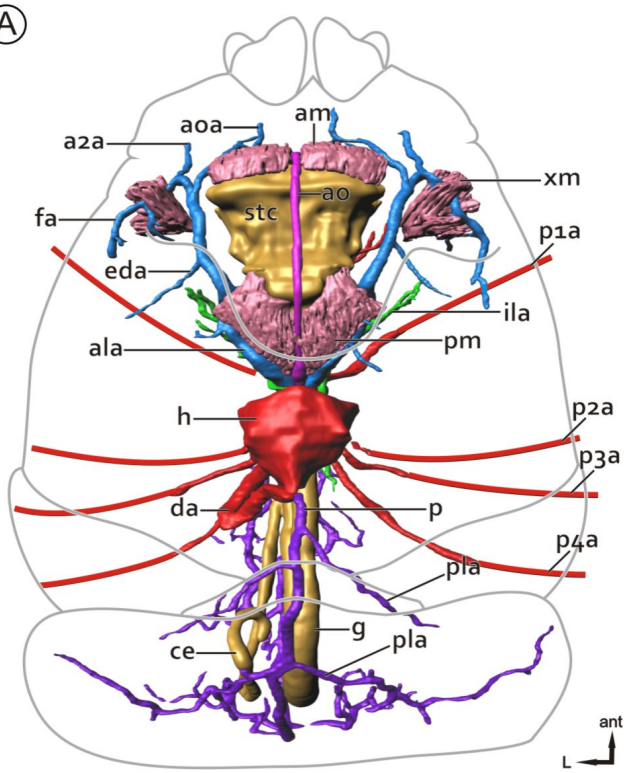

(C)

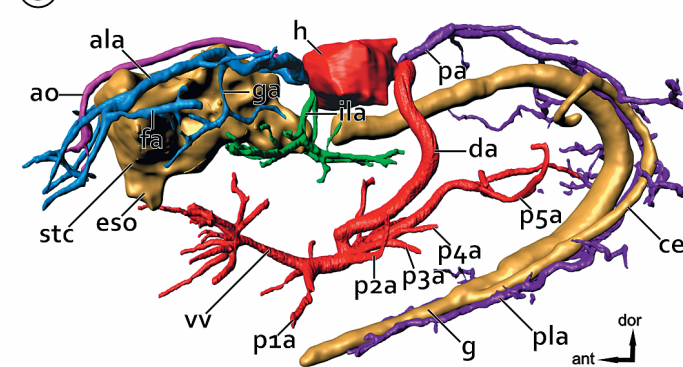

(E)

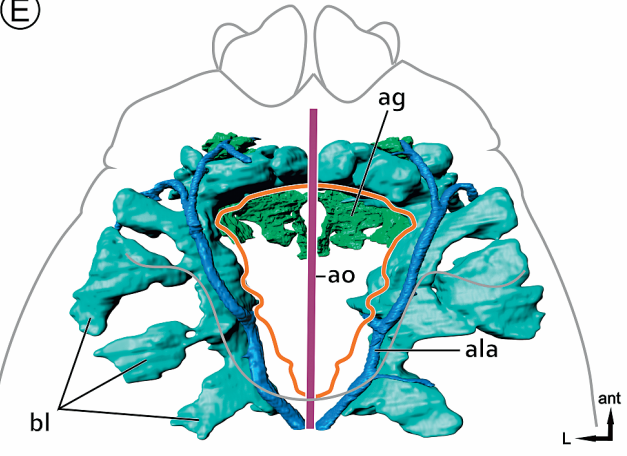

(B)

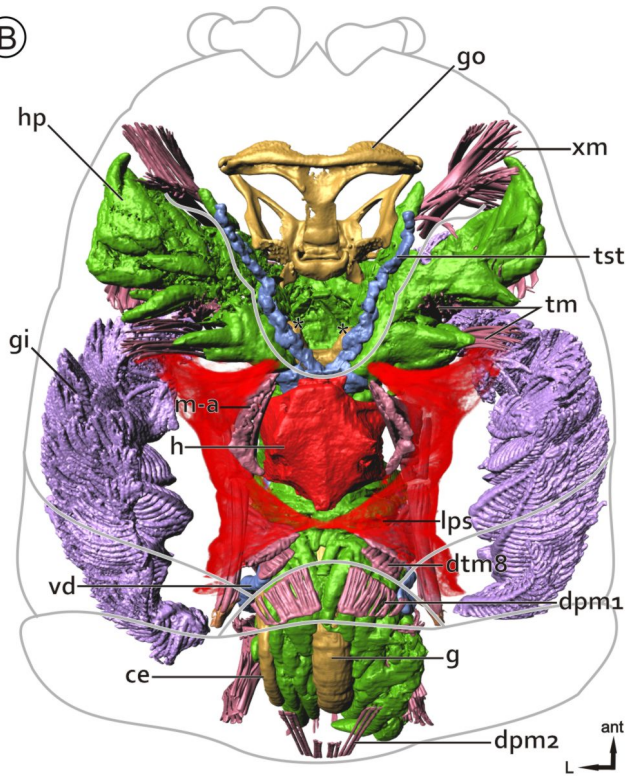

ant
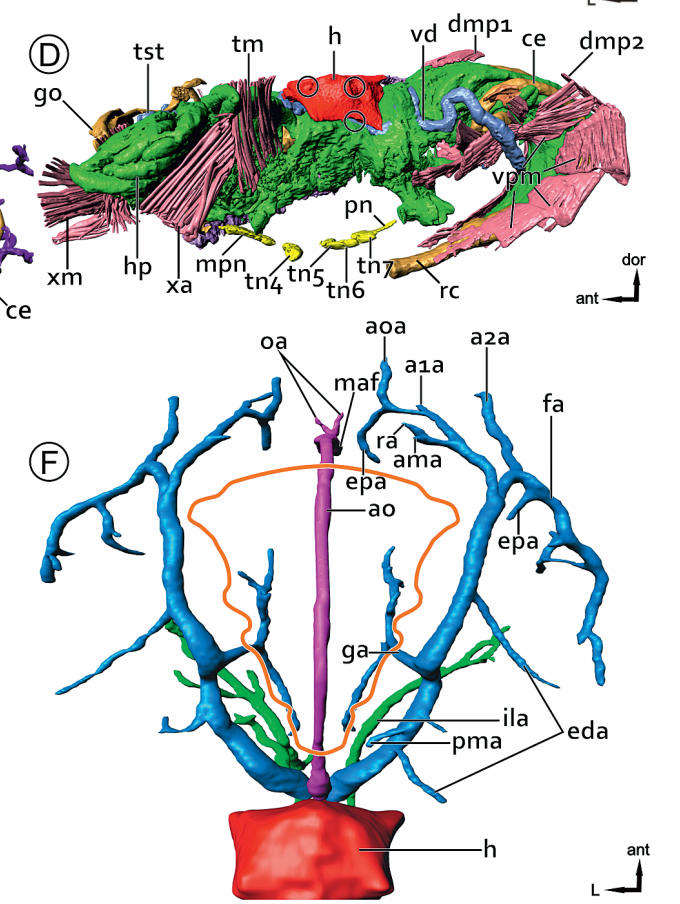

Fig. 8. Spatial relationships between the hemolymph vascular system and other internal organs (surface renderings) in Lomis hirta. PDF version contains interactive 3D content. To activate click on figures A and B in Adobe Reader. Rotate objects with mouse and see further functionalities in content menu. A+B. Dorsal view. C+D. Left-sided lateral view. E. Dorsal view revealing the extension of the antennal bladder. F. Dorsal view. Detailed branching pattern of anterior lateral arteries. Stomach is outlined in orange. Abbreviations: a1a, antennular artery; A2a, antennal artery; ag, antennal gland; ala, anterior lateral artery; am, anterior gastric muscle; ama, anterior gastric muscle artery; ao, anterior aorta; bl, antennal bladder; br, brain; ce, cecum; da, descending artery; dtm8, dorsal thoracic muscles; eda, epidermal artery; epa, epistomal artery; eso, esophagus;fa, fringe artery; g, gut; ga, gastric artery; gi, gills; go, gastric ossicles; h, heart; hp, hepatopancreas; ila, inferior lateral arteries; lps, lateral pericardial septum; pla, posterior lateral artery; $\mathrm{m}$-a, dorsal thoracic muscles; maf, widening of myoarterial formation; mpla-mp3a, maxillipedal arteries; mpn; neuropil associated with mouthparts; pla-p5a, leg arteries; pa, posterior aorta; pm, posterior gastric muscle; pma, posterior gastric muscle artery; pn, pleonal neuropils; ra, rostral artery; rc, rectum; tm, vertical thoracic muscles; tn4-7, thoracic neuropils; stc, stomach; vv, ventral vessel; xa, external antennal adductor muscles?; xm, external mandible adductor muscle. 
anteriorly and laterally to the stomach and cover a large portion of the hepatopancreas. In A. cholchol, the bladder is a twisted tubular structure (Suppl.-Fig. S5) and restricted to the anterolateral portion of the cephalothorax (Fig. 9A).

Reproductive system. In A. cholchol and L. hirta, the ovaries (ov) are paired and located dorsally to the hepatopancreas. They are connected with each other below the anterior portion of the heart (dashed green rectangle in Fig. 4A), resulting in an $\mathrm{H}$-shaped structure. Anteriorly, the lobes enfold the posterior portion of the stomach (Fig. 4A, D). Posteriorly, the lobes run into the pleon up into the third (A. cholchol: Figs. 4B, C, 6C) or sixth (L. hirta: Figs. 3G, 4E) pleonal segment. The female reproductive structures in K. puravida were not visible due to fixation artifacts. In all three species, the testes (tst) are paired and restricted to the cephalothorax (Fig. 8B). They are connected to the vasa deferentia (vd) on each side. The vasa deferentia exhibit varying degrees of convolution, running to the gonopores on the coxae of the eighth thoracic segment (Figs. 7C, 8D). In some specimens, the loops of the distal vasa deferentia reach into the first (confirmed for A. cholchol) or second pleonal segment (confirmed for L. hirta).

Endophragmal skeleton. The endophragmal skeleton is formed by endosternites and endopleurites, i.e. cuticular invaginations located between two consecutive thoracic segments (Fig. 5A-C, Suppl.-Fig. S6). In K. puravida (Fig. 5C) and L. hirta (Fig. 5B), endosternites $7 / 8$ lie closer together medially than the preceeding endosternites and form the posterior edge of the plastron, which is bent antero-dorsally. The posterior edge of the plastron in A. cholchol (Fig. 5A) is broad since the endosternites are restricted to the periphery. The inner surface of the plastron varies in texture: in A. cholchol (Fig. 5A, Suppl.-Fig. S6C) and K. puravida (Fig. 5C, Suppl.-Fig. S6B) it is relatively smooth, although in K. puravida (Fig. 5D) a dorsally directed median keel (mk) partly covered by the bent posterior edge formed by the endosternites $7 / 8$ is located anteriorly to the posterior emargination in the seventh thoracic segment. In L. hirta (Fig. 5B), a median ridge is present in segments 5-7 (i.e. a short medial keel per segment). In all three species, a thin transverse thoracic bridge (tb) connects endosternites $4 / 5$ with each other and spans the ventral portion of the cephalothorax (dashed yellow line in Fig. 5A-C and Suppl.-Fig. S6C, D). In L. hirta (Fig. 5B), a second thoracic bridge is present between endosternites 5/6. In all studied species, an endophragmal lever (lv) on each side runs between the dorsal ridge of the thoracic walls (formed by the rear thoracic pleurites and endopleurites) and the first pleonal sternites (pst1; Suppl.-Fig. S7). Attached to the lever is a bundle of adductor muscles (lvm) fixed to a dorsal evagination (arrows, Suppl.-Fig. S7) of the seventh thoracic pleurites (tpl7). The levers in K. puravida (Suppl.-Fig. S8A) are about three times longer than in A. cholchol (Suppl.-Fig. S8B) and about four times longer than in L. hirta (Suppl.-Fig. S8C).

Dorsal thoracic muscles. In the dorsal portion of the thorax, various paired bundles of muscles are suspended either between the inner side of the carapace and the endophragmal skeleton or between elements of the endophragmal skeleton (Suppl.-Fig. S7). The eighth dorsal thoracic muscles (dtm8) differ in size and position between the species: they are long and large in $K$. puravida (Fig. 3B, Suppl.-Fig. S9A), but smaller and more lateral in A. cholchol (Suppl.-Fig. S9B) and $L$. hirta (Fig. 3C, 8B, Suppl.-Fig. S9C). In K. puravida (Figs. 3B, 7A, C), two thin muscle layers (m-c) above the anterior half of the eighth dorsal thoracic muscles are suspended tent-like between the midline of the carapace and the dorsal ridges of the thoracic walls. A structure of this nature is absent in A. cholchol and $L$. hirta.

Ventral thoracic muscles. The ventral thoracic muscles (vtm) are extrinsic muscles (flexors + extensors) for the legs and are located directly above the plastron. In A.cholchol (Fig. 5A, 10C) and K. puravi$d a$ (Fig. 5E), the muscles of leg pairs p2-p3 are well separated medially), but attached to the median ridge in L. hirta (Fig. 10D). The muscles of p4 in K. puravi$d a$ and $L$. hirta are attached to the medial keel but medially separated in A. cholchol (Fig. 5A), though the distance between them is not as great as in p2-p3.

Pleonal muscles. The pleonal muscles (ventral, dorsal and lateral) differ greatly between the species. They are most pronounced in A. cholchol (Figs. 3A, D, 9, Suppl.-Figs. S8B, S9B), filling most of the pleon. In $K$. puravida (Fig. 3B, E, Suppl.-Figs. S8A, S9A), though the pleonal muscles also fill most of the pleon, the diameter of the pleonal segments is much smaller in relation to the rest of the body. In L. hirta (Fig. 3C, Suppl.-Figs. S8C, S9C), the pleonal muscles are largely reduced to thin layers while most of the pleon is filled by the gonads and the diverticles of the hepatopancreas (Fig. 3F, G). In K. puravida (Suppl.-Figs. S8A, S9A) and A. cholchol (Suppl.-Figs. S8A, S9B), the eighth dorsal thoracic muscles (dtm8) connect the dorsal pleonal muscles with the thoracopleonal extensor muscles (pxm) which are attached to the thoracic 


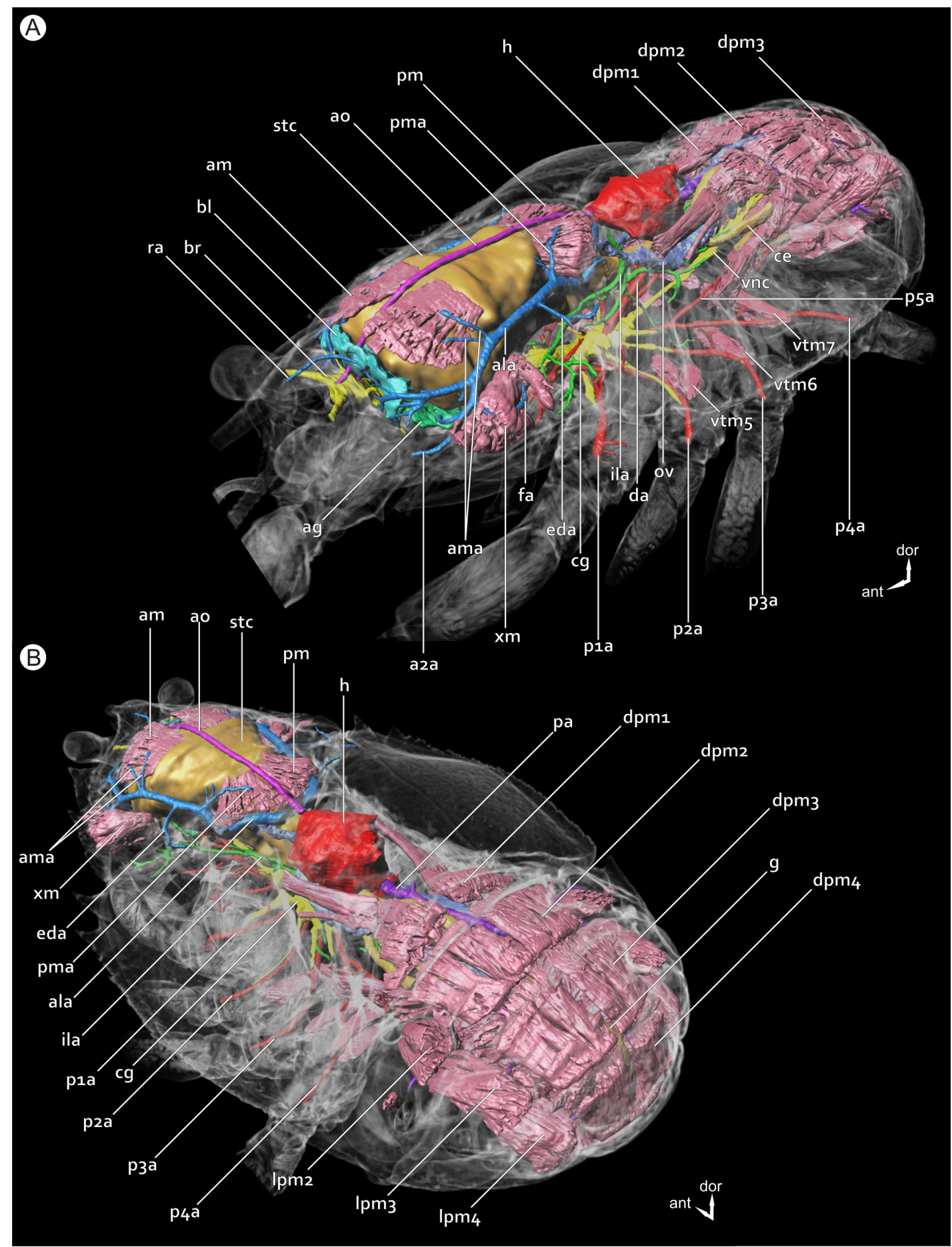

Fig. 9. Overview of the internal anatomy of Aegla cholchol (volume and surface renderings). PDF version contains interactive 3D content. To activate click on figure in Adobe Reader. Rotate objects with mouse and see further functionalities in content menu. A. Dorsolateral view from anterior. B. Dorsolateral view from posterior. Various muscles and the hepatopancreas, which fills most of the cephalothorax, are not shown. Abbreviations: a2a, antennal artery; ag, antennal gland; ala, anterior lateral artery; am, anterior gastric muscle; ama, anterior gastric muscle artery; ao, anterior aorta; br, brain; ce, cecum; cg, cephalothoracic ganglion; da, descending artery; dpm, dorsal pleonal muscles; eda, epidermal artery; fa, fringe artery; g, gut; h, heart; ila, inferior lateral arteries; lpaov, ovaries; pla-p5a, leg arteries; pa, posterior aorta; pm, posterior gastric muscle; ra, rostral artery; stc, stomach; vtm, ventral thoracic muscles; xm, external mandible adductor muscle. 

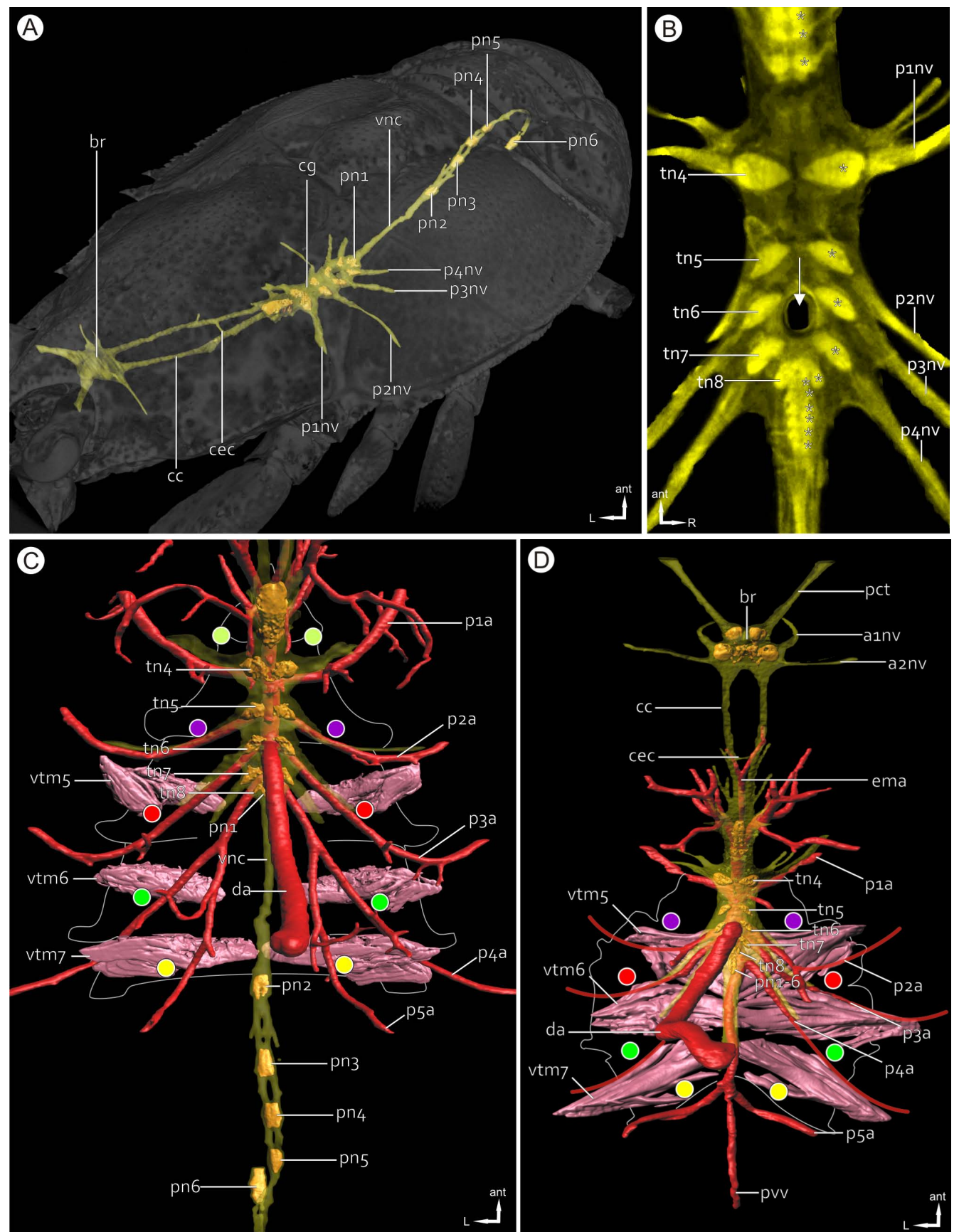

Fig. 10. Morphology and spatial relationships of the nervous system. PDF version contains interactive 3D content. To activate click on figure D in Adobe Reader. Rotate objects with mouse and see further functionalities in content menu. A. Nervous system of Aegla cholchol (surface rendering) and its position within the animal (volume rendering). Neuropils are depicted in orange. B. Cephalothoracic ganglion and fused pleonal neuromers of the ventral nerve cord in Lomis hirta (volume rendering). Asterisks indicate neuropils. Arrow indicates opening between sixth and seventh thoracic neuromers through which the descending artery passes. C-D. Ventral thoracic muscles (pink), ventral vessel system (red) and nervous system (yellow) in A. cholchol. (C) and Lomis hirta (D). Surface renderings. Medial margins of the endosternites are indicated by coloured circles. Neuropils are depicted in orange. Leg arteries in $L$. hirta are graphically enhanced. Abbreviations: br, brain; cc, circum esophageal connective; cec, circum esophageal commissure; cgm, cephalothoracic ganglion mass; da, descending artery; eg, egg; ema, esophageal-mandibular artery; mp, ganglia of the mouthparts; p1-5; leg arteries (red)/nerves (yellow); mk, medial keel; od, oviduct; on, optic neuropil; pfm, pleonal flexor muscles; pg1-6, pleonal ganglia; pvv, posterior ventral vessel; tg4-8, thoracic hemiganglion; up, uropod muscles; vtm, ventral thoracic muscles; vv, ventral vessel. 
endopleurites; the ventral pleonal muscles are coupled with the thoracopleonal flexor muscles (pfm). In $L$. hirta, the thoracopleonal flexor system is less pronounced, a thoracopleonal extensor system is not present (Suppl.-Figs. S8C, S9C).

Central nervous system. In all three species, the anteriormost part of the central nervous system is the brain (br) in the anterodorsal portion of the body. It is relatively small compared to the rest of the body (Figs. 7B, 9A) and distinct nerves (Fig. 10D) emanate to the sensory organs of the head (eyes, antennulae, antennae). A pair of circumesophageal connectives (cc, Fig. $10 \mathrm{~A}, \mathrm{D})$ connects the brain to the cephalothoracic ganglion (cg, Figs. 10, 5E). The latter includes the neuromeres of the mandibular, the first and second maxillar, the thoracic segments and the first pleonal neuromere. It is located in the anterior portion of the cephalothorax (thoracic segments th3 - th5). The paired neuropils of the anterior neuromeres (mpn), which correspond to the segments of the mouthparts, lie close together, (Figs. 8D, 10) while the neuropils of the posterior thoracic neuromers $(\operatorname{tn} 4-\mathrm{pn} 1)$, which correspond to the segments of the pereiopods, are further apart (Figs. 5E, 8D, 10). Posteriorly, the pleonal neuromeres (pn2 - pn6) are connected to the cephalothoracic ganglion via paired connectives (Fig. 10C). In K. puravida and A. cholchol, the pleonal neuromers pn2 - pn6 form separate ganglia which are arranged in an irregular segmental pattern: the last ganglion reaches into the sixth pleonal segment while the fifth (plg5) is located in the third (A. cholchol; Fig. 6C) or fifth $(K$. puravida) pleonal segment. In $L$. hirta, the pleonal neuromeres pn2 - pn6 lie close together within the seventh to eight thoracic segment and are confluent to the cephalothoracic ganglion (Fig. 10B). A schematic overview is given in Figure 5E.

Circulatory system. The terminology herein is that used by Keiler et al. (2015a, b).

\section{Hemolymph vascular system}

Heart: The heart (Figs. 6A, 7A, 8A, 9, Suppl-Figs. S10, S11) is located dorsally in the cephalothorax under the carapace and above the anterior portion of the gut, where it is suspended by several ligaments. It lies in the pericardial sinus, which is framed laterally and ventrally by the pericardial septum. The two lateral portions of the septum (lps, Fig. 8B, Suppl.-Fig. S11) are suspended vertically between the carapace and the dorsal ridges of the endopleurites, the ventral portion (not shown) is suspended horizontally close to the ven- tral side of the heart between the two dorsal ridges of the endopleurites. Within the pericardial sinus, several dorsal thoracic muscles (lvm, $\mathrm{m}-\mathrm{a}, \mathrm{m}-\mathrm{b}, \mathrm{m}-\mathrm{c})$ run lateral and posterior to the heart (Suppl.-Fig. S11). In the dorsal aspect, the heart is broad in L. hirta (Fig. 8B, Suppl.-Fig. S10C) and more slender in A. cholchol (Figs. 3A, 6A, Suppl.-Fig. S10A) and K. puravida (Fig. 7A, Suppl.-Fig. S10B). In all three species it is equipped with three pairs of ostia. These slit-like openings are arranged transversely to the anterior-posterior body axis (Fig. 8D, Suppl.-Fig. S10D). Two pairs are located dorsally (anterodorsal and posterodorsal ostia) and one pair is located ventrolaterally. Several muscle strands (myc) cross the lumen of the heart. While the overall shape of the heart is broadly symmetrical, most strands of the myocard appear to be arranged asymmetrically (Suppl.-Fig. S10F, G).

Arterial Systems: Five artery systems emanate from the heart: the unpaired anterior aorta system, the paired anterior lateral artery systems, the paired inferior lateral artery systems, the unpaired posterior aorta system and the ventral vessel system. The latter consists of the vertical descending artery and the horizontal ventral vessel. The proximal portion of all these cardiac vessels lies within the pericard.

Anterior aorta system: The anterior aorta (ao) emanates anteriorly from the heart, passes the posterior gastric muscles and runs in an anterior direction above the stomach and just below the carapace into the cephalic region, passing the anterior gastric muscles on its way (Figs. 6C, 7A, 8A, 9). Above the brain, the unpaired brain artery (ba) branches off and descends ventrally into the brain where it turns anteroventrally and bifurcates. Both branches then turn in a posterior direction towards the olfactory lobes of the brain. A myoarterial formation (maf) is observable as a slight widening of the anterior aorta (Fig. 8F) directly posterior to the brain artery and flanked by two vertical muscles strands suspended anteriorly of the stomach between the carapace and the esophagus (Suppl.-Fig. S12). The anterior aorta continues anteriorly and bifurcates into the optic arteries (oa) which run into the eye stalks (Figs. 6A, B, 8F; not seen in K. puravida).

Anterior lateral artery systems: A pair of anterior lateral arteries (ala) emanates from the heart directly laterally to the anterior aorta. Each anterior lateral artery runs (above the anterior lobes of the gonads and the antennal bladder) in an anterior direction at a lateral angle of approximately $45^{\circ}$ and then follows an almost parallel course to the anterior aorta (Figs. 6A, $7 \mathrm{~A}, 8 \mathrm{~F})$. Laterally, the anterior lateral arteries give rise 

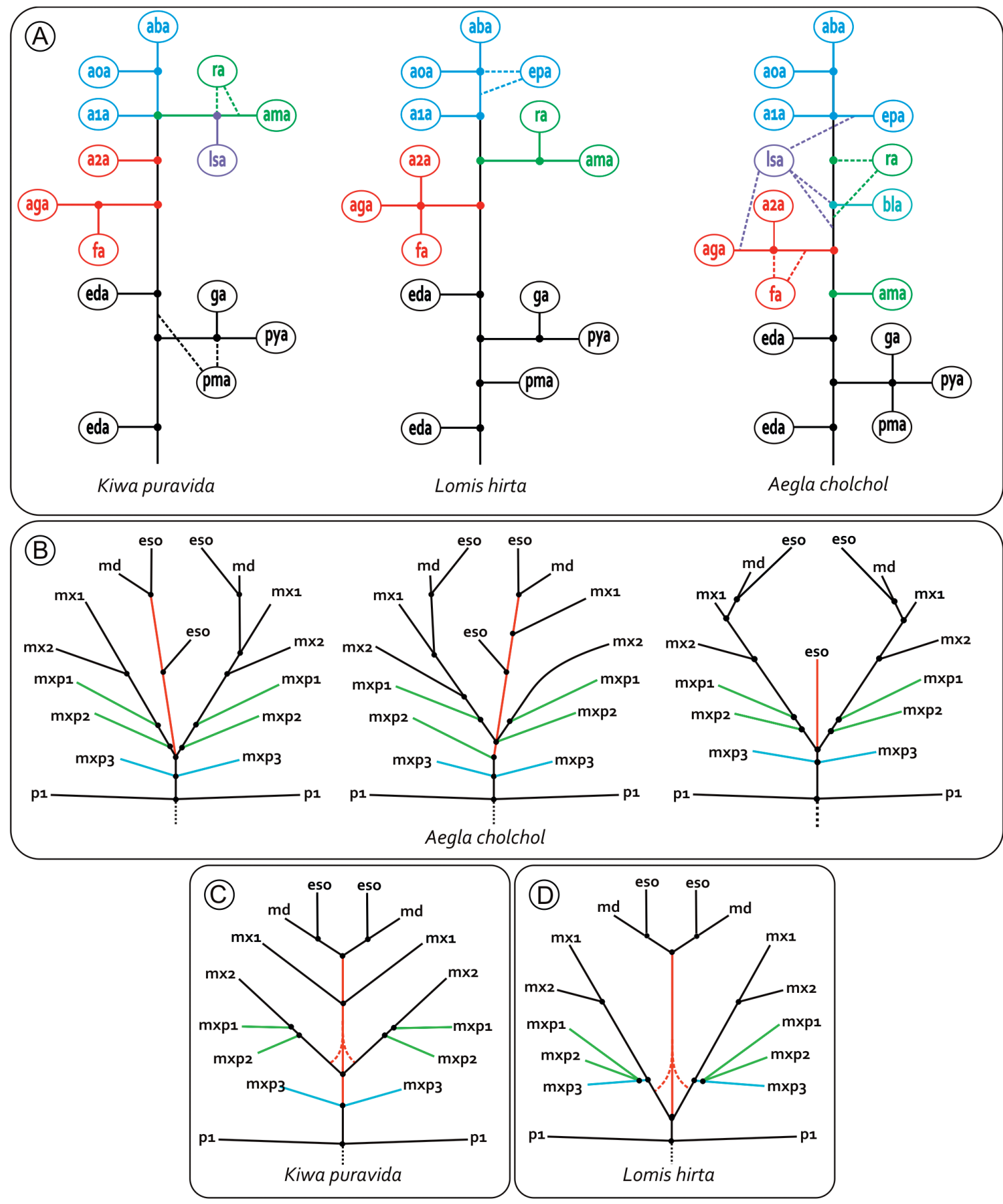

Fig. 11. Schematic vascular trees illustrating the gross topology of the various distinct arterial patterns observed in the studied species. Variable arterial roots are indicated by dashed lines. A. Anterior lateral artery system. Labels in circles represent the terminal arteries. The same combinations of arteries are shown in the same colours. Distances between the nodes do not reflect the natural proportions (see e.g. Fig. 8F). B-D. Mouthpart arteries. Distances between the nodes only roughly reflect the natural proportions (see Suppl.-Fig. S13A-F). Abbreviations: a1a, first antennal artery; a2a, second antennal artery; aba, accessory brain artery; aga, antennal gland artery; ama, anterior gastric muscle artery; aoa, accessory optic artery; bla, bladder artery; epa, epistomal artery; eda, epidermal artery; eso, esophagus; fa, fringe artery; ga, gastric artery; 1sa, lateral spine artery; md, mandibular artery; mx1-mx2, maxillar arteries; mxp1mxp3, maxillipedal arteries; p1, $1^{\text {st }}$ pereiopod; pma, posterior gastric muscle artery; pya, pyloric artery; ra, rostral artery. 

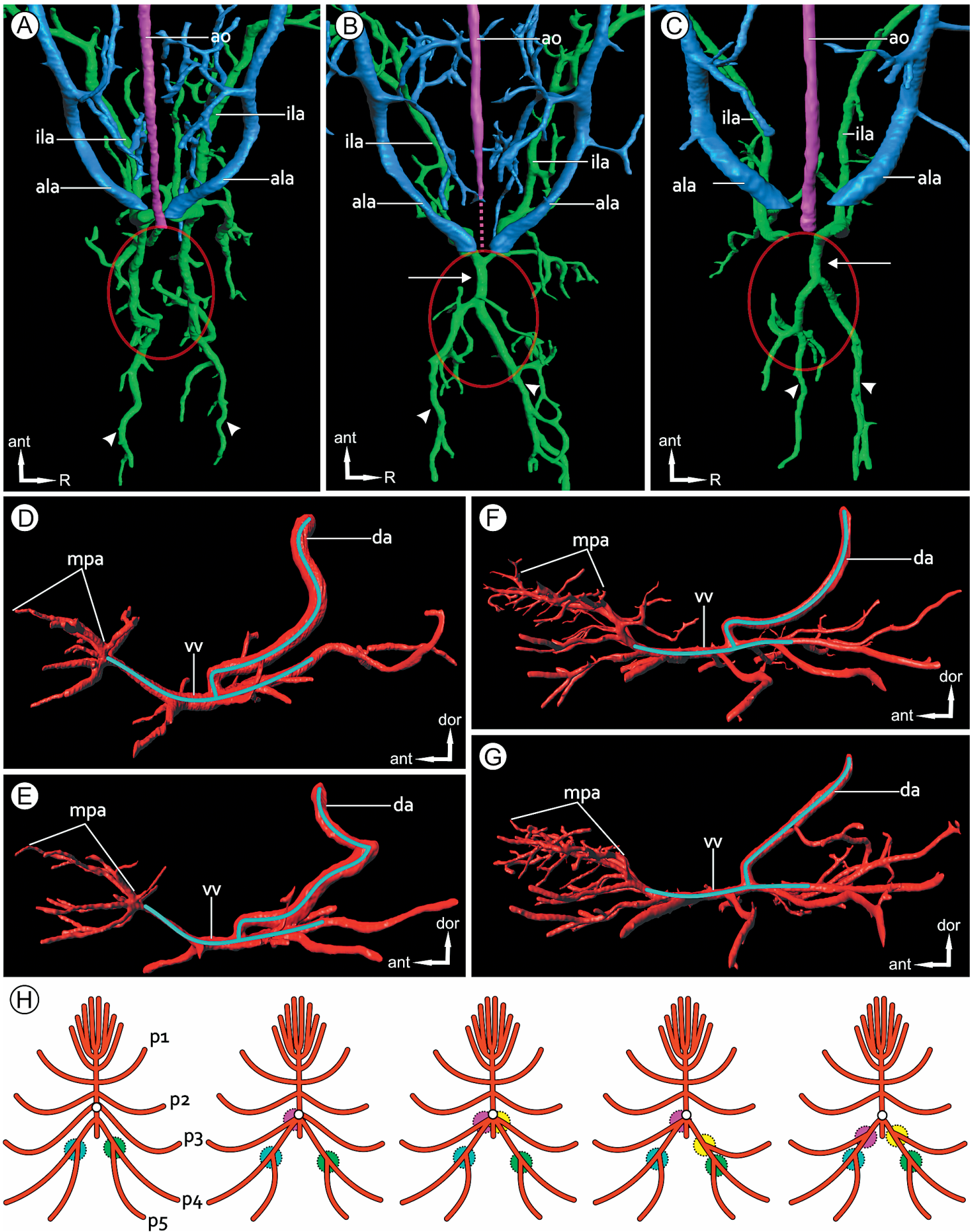

Fig. 12. Intraspecific arterial variability and interspecific arterial variation. A-C. Aegla cholchol. The paired posterior branches (arrowheads) of the inferior lateral arteries (ila) either emanate separately (A) or feed on an unpaired posterior branch (arrow) of either the left (B) or right (B) ila. Oval circle indicates position of the heart. D-G. Difference in course of the descending artery in Lomis hirta (D, E) and A. cholchol (F, G). Projected center line indicates course of descending artery and ventral vessel. H. Variable branching pattern of the leg arteries in A. cholchol. Colour coded areas indicate a common branch. 
to several laterally directed and variably arranged arteries (eda) which mainly supply the epidermis and which run to the periphery of the carapace (Figs. 6C, $7 \mathrm{~A}, 8 \mathrm{~A}, \mathrm{~F}, 9$ ). Medially, the gastric artery (ga) emanates and supplies the lateral muscles of the stomach (gastric mill) and the pylorus. While the dorsal posterior gastric muscles in K. puravida and A. cholchol are supplied by a side branch of the gastric artery, they are supplied in L. hirta by a separate branch (pma, posterior gastric muscle artery) emanating directly from the anterior lateral arteries. In the cephalic region, a distinct set of arterial branches (defined by their target organ or region) is present and can be broken down as follows (see Fig. 11A):

Anterolaterally, a branch turns laterally and then backwards giving off several smaller arteries which supply the external mandible adductor muscles (xm, Figs. 6A, 8A, 9A). It then (as confirmed in A. cholchol and $L$. hirta) continues in a posterior direction (fa, fringe artery) along the branchiostegites. Anteriorly, a side branch runs into the second antennae (a2a, antennal artery). Ventromedially, a branch (aga, antennal gland artery) runs into the antennal gland (Suppl.-Fig. S4A).

Dorsomedially, a branch emanates which in $K$. puravida and $L$. hirta bifurcates into the arteries which supply the rostrum (ra, rostral artery) and the anterior gastric muscles (ama, anterior gastric muscle artery) (Figs. 6C, 9). In A. cholchol, the two arteries emanate separately.

Distomedially, a branch splits to supply the first antennae (a1a, antennular artery), the eye-stalk (aoa, accessory optic artery), the brain (aba, accessory brain artery) (Fig. 8F) and the epistome (epa, epistomal artery).

In A. cholchol, a medially directed artery (bla) emanates from the anterior lateral arteries and runs between the loops of the antennal bladder. This artery is not present in K. puravida and L. hirta. The branching pattern of the anterior lateral arteries in A. cholchol was found to be highly variable both between specimens and between the left and the right artery (Fig. 11A).

Inferior lateral artery systems: A pair of inferior lateral arteries (ila) branch off directly beneath the anterior lateral arteries, continue their course ventrally (Figs. 6C, 7C, 8C) and each bifurcate into an anterior and a posterior branch which in turn give rise to several branches supplying the hepatopancreas. Both the anterior and posterior branches roughly follow the course of the hepatopancreas: while the posterior branch is basically straight, the anterior branch is bent anterolaterally. The situation in K. puravida (Fig. 7C) differs from that in A. cholchol and L. hirta in that the anterior branches ascend and run above the anterior lateral arteries.

While symmetrical anterior branches were found in all specimens of A. cholchol, the pattern of the posterior branches is variable in this species: some specimens display a left or right posterior branch only which bifurcates and supplies both the left and right bunch of the hepatopancreas, while the contralateral branch is reduced (Fig. 12B, C).

Posterior aorta system: The posterior aorta (pa) emanates from the posteroventral portion of the heart and runs above the gut and between the dorsal and ventral pleonal muscles in a posterior direction. The proximal section bifurcates into two equally sized main arteries: the left (lpa) and right pleonal artery (rpa) which run parallel on each side of the gut towards the end of the pleon into the telson (Fig. 4E, F). The length of the unpaired proximal section of the posterior artery differs between the studied species (Fig. 4G): In A. cholchol (Figs. 4A-C, GII, 6A), the point of bifurcation into the pleonal arteries is located between the last thoracic and the first pleonal segment; in $L$. hirta (Fig. 4E, F, GIII), the bifurcation is located in the fourth pleonal segment. The unpaired section is most extended in K. puravida (Fig. 4GI), with the bifurcation occurring between the fifth and sixth pleonal segments.

Along the way, several paired lateral vessels (posterior lateral arteries, pla) emanate segmentally (Fig. 4), mainly supplying the pleonal muscles (and, if present, the pleopods). In the sixth pleonal segment (pl6), two pairs of lateral arteries are present; one anterior pair supplying the pleonal muscles and one posterior pair running into the uropods (up). In addition, several scattered vessels emanate medially from the pleonal arteries and supply the gut.

Ventral vessel system: The ventral vessel system is made up of the descending artery (da) and the ventral vessel (vv) and its side branches and mainly supplies the ventral nerve cord (vnc), the legs (pereiopods p1p5) and the mouthparts.

The descending artery, which has the greatest diameter of all the vessels branching off the heart, emanates from the left side of the posteroventral part of the heart, directly beside the root of the posterior aorta, and runs ventrally (Figs. 3A, 8A, C). In almost all studied specimens (see Tab. 1), the descending artery crosses the gut on the left and therefore takes a slightly 
left-hand course (Figs. 8A, 10D). The artery proceeds ventrally, pierces the ventral nerve cord between the sixth and seventh neuromeres $(\operatorname{tn} 6+\operatorname{tn} 7)$ and merges into the ventral vessel below (Fig. 10C, E). The ventral vessel gives rise to the paired leg arteries (pla-p5a) and to the artery systems supplying the mouthparts (Fig. $5 \mathrm{E})$. Anteriorly, the ventral vessel terminates in the arteries which supply the mandibles and esophagus; posteriorly, it terminates in the posterior ventral vessel (pvv) that runs into the pleon (Figs. 5A, C, 10D). The ventral vessel system supplies the cephalothoracic ganglion via several ascending arteries (asterisks in Fig. 5A, D) which run between the neuromeres.

The merging point and course of the descending artery and the angle between the leg arteries differ between the species. The descending artery merges with the ventral vessel either between the second and third leg arteries (p2a-p3a) (Fig. 10D) or at the level of the third leg arteries (p3a) (Figs. 5D, 10C; see also Tab. 1). Despite these differences, the merging point of the descending artery and ventral vessel is always located in the fourth thoracic segment, taking the ventral thoracic muscles (vtm) as a reference. In K. puravida, the descending artery takes a slightly curved antero-ventral course before piercing the ventral nerve cord (Fig. 7C). The course of the descending artery in L. hirta (Fig. 12D, E) and A. cholchol (Fig. 12F, G) is variable. The ventral vessel in A. cholchol follows a level course, while that in K. puravida (Fig. 5D) and L. hirta (Fig. 12D, E) runs above the median keel or median ridge of the plastron, respectively, resulting in a distinct posterior rise.

Before the leg arteries run into the respective leg, they proceed between the cuticular walls formed by the endosternites and endopleurites (Fig. 5A, C). The angles at which the leg arteries (p1a-p5a) emanate as well as the distances between the pairs of leg arteries differ between the species. In $K$. puravida, the leg arteries emanate successively at roughly equal intervals (Fig. 5C, E, Suppl.-Fig. S6A, B). The arteries of p1 emanate at about $30^{\circ}$ anteriorly, of $\mathrm{p} 2$ at about $90^{\circ}$ and of p3-p5 at about $40-50^{\circ}$ posteriorly. In L. hirta on the other hand, leg arteries pla-p4a emanate close together, while p5a emanates some distance posteriorly (Figs. 10D, 5E). The arteries of $\mathrm{pl}$ emanate at about $30^{\circ}$ anteriorly, and of $\mathrm{p} 2-\mathrm{p} 5$ at about $30-50^{\circ}$ posteriorly. The pattern of leg arteries in A. cholchol is variable and was asymmetrical in some specimens (Fig. 12H). However, in all specimens, the fifth leg arteries (p5a) emanated from the fourth leg arteries.

From the proximal portion of leg arteries pla-p4a a pronounced branch (arrowheads in Fig. 5A) runs dor- sally and supplies the leg muscles between the thoracic walls.

Arterial supply to the mouthparts: In the cephalic region, the ventral vessel ascends at an angle of 30-45 (Fig. 12D-G) and terminates in the mouthpart arteries. The mouthpart arteries originate from the anterior part of the ventral vessel. In A. cholchol and L. hirta, the ventral vessel bifurcates anteriorly at the level of endosternites 3/4, in K. puravida (Suppl.-Fig. S13E), the point of bifurcation is further anterior. Successive side branches run into the maxillipeds (mxp1-mxp3) and the first and second maxillae $(\mathrm{mx} 1, \mathrm{mx})$ (Fig. 11B-D, Suppl.-Fig. S13). The roots of the arteries to mxp1 and mxp2 generally lie close together. In A. cholchol (Fig. 11B, Suppl.-Fig. S13A-C) and K. puravida (Fig. 11C, Suppl.-Fig. S13D, E), the arteries of the third maxillipeds emanate posterior to the bifurcation of the ventral vessel, in L. hirta (Fig. 11D, Suppl.-Fig. S13F), anterior to it. The branching pattern of the arteries supplying the maxillae, mandibles and esophagus in A. cholchol is highly variable (Fig. 11B, Suppl.-Fig. S13A-C).

\section{Hemolymph lacunar system}

After leaving the vascular system, hemolymph is channelled (back) to the heart via lacunae and sinuses. The most distinct sinuses are the branchiopericardial sinuses, which channel hemolymph from the paired gills (phyllobranchs in K. puravida (Fig. 7A, B); trichobranchs in A. cholchol (Fig. 6A, B) and L. hirta (Fig. $8 \mathrm{~B})$ ) to the pericardial sinus. A large lacunar meshwork (bsl) is found between the epidermal layers of the branchiostegites, covering their posterior and posterolateral regions (Fig. 6A, B; confirmed in A. cholchol). It is connected to the pericardial sinus via channel-like sinuses.

\section{Discussion}

To comprehend the evolutionary morphological transformations undergone in Chirostyloidea, Aegloidea and Lomisoidea in general and those undergone in $\mathrm{Lo}$ mis hirta and carcinization in particular, it is necessary to reconstruct the morphology of the last common ancestor of Chirostyloidea, Aegloidea and Lomisoidea. We consider those characters which are either shared by Galatheoidea (as outgroup) and one of the studied species or which are shared by all (or at least Kiwa puravida and Aegla cholchol) species as belonging to the ground pattern of Australopoda. 
Since there is no consensus as to whether Aegloidea or Chirostyloidea is the sister group to Lomisoidea, we restrict our discussion largely to the morphological transformations from the Australopoda ground pattern to the representatives of Kiwa, Aegla and Lomis studied herein. Going by the phylogenies proposed by Schnabel et al. (2011) and Bracken-Grissom et al. (2011), it appears possible that the last common ancestor of all anomurans possessed a squat lobster-like habitus (see also Haug and Haug, 2014). The ancestral state reconstruction put forward by Bracken-Grissom et al. (2013) suggests that Australopoda has derived from a squat lobster-like ancestor itself, a hypothesis based on the sister group relationship of the Galatheoidea and Australopoda (for a detailed description of the anatomical ground pattern of Galatheoidea see Keiler et al.2015a). This is the scenario which we also favour. In conclusion, there can be little doubt that Lomis is derived from a squat lobster-like ancestor.

The anatomy of the last common ancestor of Chirostyloidea, Aegloidea and Lomisoidea - the ground pattern of Australopoda

If we accept that a more or less squat lobster-like appearance is present in the ground pattern of Australopoda, we can assume that the external morphology corresponded broadly with that of galatheoid squat lobsters and Aegla in having a carapace slightly longer than it was broad, pleonal segments 1-4 visible from above and a plastron with an almost straight posterior margin possibly not covered by the bent pleon. Although Aegla broadly reflects the external morphology of the ground pattern of Australopoda, certain internal characters seem to be highly derived in the freshwater anomurans (Tab. 1). The tubular structure of the antennal bladder in Aegla is most probably derived since Lomis, Kiwa and Galatheoidea (see Keiler et al., 2015a) possess a lobed bladder, which in turn reflects the condition in the ground pattern of Australopoda. The tubular bladder resembles the tubular intervening duct of the antennal glands in crayfish (see Marchal, 1892), with both appearing to be an adaptation to a freshwater lifestyle (McNamara et al., 2015).

\section{The morphological ground pattern of Chirostyloidea and the evolution of Kiwaidae}

On the basis of their overall proportions in the dorsal view, Kiwa and Aegla can both be regarded as squat lobsters. They do differ from each other; however, in the proportions of their carapace and the shape of their pleon (see Fig. 2H). While Aegla displays proportions corresponding to those of galatheoid squat lobsters (Keiler et al., 2015a), Kiwa possesses a strongly bent pleon which is actually a feature of a crab-like habitus. The longer carapace in Kiwa, however, compensates for this shortening and imparts the overall squat lobster-like habitus. The proportions of Kiwaidae are probably derived within Chirostyloidea, since the two other chirostyloid taxa Eumunididae and Chirostylidae (of whose fresh material was unfortunately not available for this study) have proportions more similar to those in galatheoid squat lobsters (see Schnabel and Ahyong, 2010) and reflect the chirostyloid ground pattern (see also phylogeny in Roterman et al., 2013). The triangular posterior emargination of the plastron probably evolved independently in Kiwa and Lomis since a pronounced emargination of the plastron is not present in Eumunididae or Chirostylidae (see e.g. Baba et al., 2009).

The evolution of the sternal plastron and its impact on internal anatomy

The presence of a broad sternal plastron seems to be a prerequisite for the compaction and anterior shift of the cephalothoracic ganglion brought about by the disappearance of the barriers formed by the endosternites. The cephalothoracic ganglion in Aegla, Kiwa, Lomis and thus in the ground pattern of Australopoda is similarly compact as in Galatheoidea, but located more anteriorly than in Galatheoidea (Keiler et al., 2015a). Its compactness sets it apart from the more elongated form found in other decapods such as homarid lobster or axiid mud shrimp (see Bouvier, 1889). In lobsters, crayfish and mud shrimps, in which a broad plastron is not present, the endophragmal skeleton forms a narrow scaffold (see e.g., Secretan, 1998) restricting the leg nerves and thus exerting a constraint on the form of the cephalothoracic ganglion. The leg arteries in the ground pattern of Australopoda emanated separately and at roughly equal distances from each other, similarly to the situation in Kiwa (Fig. 5E) and galatheoid squat lobsters (see Keiler et al., 2015a). The fusion of the posterior leg arteries only appeared in the lineage leading towards Aegla. The position of and distances between the roots of leg arteries pla-p4a correlate roughly with the position of the cephalothoracic ganglion and the degree of compaction of the neuropils (Fig. 5E). Though hemolymph supply to the cephalothoracic ganglion is affected by the ascending 
arteries which run between the roots of the leg arteries, the ascending arteries and the position of leg arteries pla-p4a seem, at least to some degree, to be structurally dependent from, i.e. coherent with, each other. In other words, if the cephalothoracic ganglion and thus the ascending arteries became shifted anteriorly along the ventral vessel, the roots of leg arteries pla-p4a became also shifted anteriorly. Or alternatively, the anterior shift in the joint between the ventral vessel and the descending artery (which is constrained by the need to puncture the cephalothoracic ganglion) possibly necessitated an anterior shift in the leg artery roots to ensure sufficient hemolymph supply to the legs by shortening the distance the hemolymph is required to flow.

\section{Carcinization had an impact on the morphology of the cephalothorax in Lomis}

In Lomis, endosternites 7/8 form a narrow passage, promoting the more posterior branch-off of the fifth leg arteries and thereby extending the distance between the fourth and fifth leg arteries, a situation similar to that in porcelain crabs (see Keiler et al., 2015a). In both Lomis and porcelain crabs, the narrow passage is caused by the posterior emargination of the plastron necessitated by the bend in the pleon which, in turn, is a direct result of carcinization. Curiously enough, the same posterior emargination and resulting narrow passage between the endosternites is found in Kiwa, too. The pattern of leg arteries in Kiwa, however, only slightly resembles that in Lomis, mainly as a result of the larger cephalothoracic ganglion in Kiwa whose larger neuropils (Fig. 5E) necessitate greater distances between the ascending arteries and thus between the leg arteries (see discussion above). The small but numerous endophragmal keels (together forming the median ridge) in Lomis serve as a structure for extra muscle attachment. A medial keel like that in Kiwa is also present in porcelain crabs (Keiler et al., 2015a), and both have a similar function to the median ridge in Lomis, compensating the loss of attachment area caused by the posterior emargination and the shortening of the midline of the plastron. In Kiwa and Lomis, the posterior margin of the plastron is elevated, forcing the ventral vessel to take a slightly elevated course. We assume that the cephalothoracic ganglion in the ground patttern of Australopoda was already located so far anterior that the emergence of a posterior emargination of the plastron did not have a significant effect on its position in Kiwa or Lomis, unlike in the evolution of porcelain crabs (see Keiler et al., 2015a).
Morphological transformations in the pleon-pleonal muscle reduction in Lomis is a result of carcinization

Besides the shape of the ventral vessel system, Lomis possesses several other internal anatomical features whose morphology obviously changed in coherence with external morphological transformations in the course of carcinization. The most obvious of these changes are associated with the pleon. While the ground pattern of Australopoda exhibits a pleon similar to that in Aegla or galatheoid squat lobsters, i.e. incompletely bent and featuring strong muscular bundles (Fig. 3D), Lomis evolved a flattened, more strongly bent pleon whose muscles are largely reduced (Fig. $3 \mathrm{~F})$, implying that it sees less active movement than in the ground pattern of Australopoda. The pleon in Aegla still permits a caridoid escape reaction ('tail flipping'; our own observations; Martin and Abele, 1988) similar to that found in macruran decapods. In Lomis, however, the escape reaction has been lost completely in accordance with the species' lifestyle hidden under stones in the intertidal zone (our own observations). A similar evolutionary scenario has been described for porcelain crabs (Keiler et al., 2015a), though the pleonal muscles in porcelain crabs are less drastically reduced than in Lomis and some porcelain crab species seem to have retained the ability to rapidly flip their pleon (Števčić, 1971; Hiller et al., 2010). The reduction of the pleonal muscles in Lomis in turn provided more space for the ovaries, a similar phenomenon to that which occurred in the evolution of porcelain crabs (Keiler et al., 2015a).

The anterior shift and compaction of the pleonal ganglia in Lomis is coherent with a crab-like habitus

As well as the pleonal muscles, the pleonal ganglia in Lomis also underwent changes in morphology in the course of carcinization. In the ground pattern of Australopoda, pleonal ganglia pn2-pn6 were probably arranged segmentally, one per segment, and at roughly the same distances from each other, a condition seen in Kiwa and galatheoid squat lobsters (see Keiler et al., 2015a). Pleonal ganglia play an important role in controlling the caridoid escape reaction and other rapid pleonal movements (e.g. Paul, 1989, 2003; Faulkes, 2008). Decapods which exhibit a high level of pleonal activity all possess segmentally arranged pleonal ganglia (see e.g. Bouvier, 1889; Jackson, 1913; Siller and Heitler, 1985; Paul, 2004). The pleonal ganglia in Lomis are proportionally smaller than in Aegla and Kiwa 
and situated much more anteriorly in the rear cephalothorax, a shift which possibly occurred in response to the loss of the caridoid escape reaction and to the hidden lifestyle. This transformation in the pleonal ganglia may thus also have been (indirectly) affected by carcinization, a theory corroborated by findings in other crab-like taxa (see Keiler et al., 2015a, b). A comprehensive review covering the similar morphological transformations in the independently evolved crab-like habitus, associated coherences and their relevance for convergent evolution is in preparation (Keiler et al., in prep.).

\section{Conclusion}

Aegla, Kiwa and Lomis each possess unique anatomical peculiarities which reflect their independent evolution. Despite this, they can all be traced back to a squat lobster-like ancestor whose morphology was similar to galatheoid squat lobsters. The crab-like Lomis derived from this ancestor and evolved several internal anatomical features brought forth as a result of the external changes which took place in the course of carcinization. These features resemble those in other forms with a crab-like habitus, especially porcelain crabs which likewise evolved from a squat lobster-like ancestor and thus had similar predispositions.

\section{Acknowledgements}

The authors would like to cordially thank Robert 'Bob' Mesibov (University of Tasmania) for actively assisting us with collecting $L$. hirta specimens. We are also grateful to Alastair Richardson (University of Tasmania) for his assistance with permits and logistics and to Michael Driessen (University of Tasmania) for his advice on applying for collecting permits. We thank Joanne 'Jo' Taylor (Museum Victoria) for her contribution of L. hirta specimens, and Andrew Thurber (Oregon State University) for $K$. puravida. Samples of $K$. puravida were collected under US NSF OCE-0826254 and OCE0939557 grants to Lisa A. Levin (Scripps Institution of Oceanography). A. cholchol was collected by CSW during a field trip to Chile sponsored by the German Science Foundation (DFG; grant number WI3334/4-1). The authors would also like to thank the staff of the Electron Microscopy Centre (University of Rostock) for assistance with critical point drying. Peter Michalik and his colleagues (Zoological Institute, University of Greifswald) are thanked for providing their microCT for some scans. Lucy Cathrow helped to improve the English of the text. Finally, thanks go to the authors' colleagues at the Zoological Institute of the University of Rostock and two anonymous reviewers for comments and suggestions which improved the manuscript; and the German Sci- ence Foundation for funding this study (grant numbers WI 3334/1-2 and 3334/3-1). MicroCT machines are sponsored by the Deutsche Forschungsgemeinschaft DFG INST 264/38-1 FUGG (Universitaet Rostock), and DFG INST 292/119-1 FUGG, DFG INST 292/120-1 FUGG (Universitaet Greifswald).

\section{References}

Baba K, Macpherson E, Lin, CW, Chan TY. 2009. Crustacean Fauna of Taiwan: Squat lobsters (Chirostylidae and Galatheidae). Keelung: National Taiwan Ocean University.

Balss H. 1957. Decapoda. VIII. Systematik. Pp. 1505-1672 in: Bronn HG, ed., Klassen und Ordnungen des Tierreichs. Fünfter Band, 1. Abteilung 7, Buch 12. Leipzig/Heidelberg: Winter.

Boas JEV. 1880a. Lithodes und Pagurus. Zoologischer Anzeiger 3: $349-352$.

Boas JEV. 1880b. Studier over Decapodernes Slaegtskabsforhold. Det Kongelige Danske Videnskabernes Selskabs Skrifter 6, Naturvidenskabelig og Mathematisk Afdelinger I.2: 27-210.

Boas JEV. 1926. Zur Kenntnis symmetrischer Paguriden. Det Kongelige Danske Videnskabernes Selskabs, Biologiske Meddelelser V 6: 1-52.

Borradaile LA. 1916. Crustacea. Part II. Porcellanopagurus: An instance of carcinization. Natural History Report. Zoology 3: 111-126.

Bouvier EL. 1889. Le système nerveux des crustacés décapodes et ses rapports avec l'appareil circulatoire. Annales Des Sciences Naturelles, Zoologie 7: 73-106.

Bouvier EL. 1895. Recherches sur les affinites des Lithodes \& des Lomis avec les Pagurides. Annales Des Sciences Naturelles, Zoologie 7: 157-213.

Bouvier EL. 1896. Sur l'origine homarienne des crabs: etude comparative des dromiacés vivants et fossiles. Bulletin de la Société Philomathique de Paris 8: 34-110.

Bracken-Grissom HD, Cannon ME, Cabezas P, Feldmann RM, Schweitzer CE, Ahyong ST, Felder DL, Lemaitre R, Crandall KE. 2013. A comprehensive and integrative reconstruction of evolutionary history for Anomura (Crustacea: Decapoda). BMC Evolutionary Biology 13: 1-28.

DeGrave S, Pentcheff ND, Ahyong ST, Chan TY, Crandall KA, Dworschak PC, Felder DL, Feldmann RM, Fransen CHJM, Goulding LYD, Lemaitre R, Low MEY, Martin JW, Ng, PKL, Schweitzer CE, Tan SH, Tshudy D, Wetzer R. 2009. A classification of living and fossil genera of decapod crustaceans. Raffles Bulletin of Zoology 21: 1-109.

Faulkes Z. 2008. Turning loss into opportunity: The key deletion of an escape circuit in decapods crustaceans. Brain Behavior and Evolution 72: 251-261.

Haug JT, Haug C. 2014. Eoprosopon klugi (Brachyura) - the oldest unequivocal and most "primitive" crab reconsidered. Palaeodiversity 7: 149-158.

Henderson JR. 1888. Report on the Anomura collected by H.M.S. Challenger during the years 1873-1876. Pp. I-XI, 1-221 in: Murry J, ed., Report on the scientific results of the voyage of H.M.S. Challenger during the years 1873-76. Zoology, Vol. 27. London: Eyre \& Spottiswoode. 
Hiller A, Viviani CA, Werding B. 2010. Hypercarcinisation: an evolutionary novelty in the commensal porcellanid Allopetrolisthes spinifrons (Crustacea: Decapoda: Porcellanidae). Nauplius 18: 95-102.

Jackson HG. 1913. Eupagurus. LMBC Memoirs on typical British Marine Plants and Animals 21: 1-79.

Keiler J, Richter S. 2011. Morphological diversity of setae on the grooming legs in Anomala (Decapoda: Reptantia) revealed by scanning electron microscopy. Zoologischer Anzeiger 250: 343-366.

Keiler J, Richter S, Wirkner CS. 2013. Evolutionary Morphology of the Hemolymph Vascular System in Hermit and King Crabs (Crustacea: Decapoda: Anomala). Journal of Morphology 274: 759-788.

Keiler J, Richter S, Wirkner CS. 2015a. Evolutionary morphology of the organ systems in squat lobsters and porcelain crabs (Crustacea: Decapoda: Anomala): An insight into carcinization. Journal of Morphology 276: 1-26.

Keiler J, Richter S, Wirkner CS. 2015b. The anatomy of the king crab Hapalogaster mertensii Brandt, 1850 (Anomura: Paguroidea: Hapalogastridae) - new insights into the evolutionary transformation of hermit crabs into king crabs. Contributions to Zoology 84: 149-165.

Lamarck JPBA. 1818. Les crustacés. (Crustacea.). Pp. 109-273 in: Histoire naturelle des animaux sans vertèbres, tome 5, Paris: Verdière.

MacPherson E, William J, Segonzac M. 2005. A new squat lobster family of Galatheoidea (Crustacea, Decapoda, Anomura) from the hydrothermal vents of the Pacific-Arctic Ridge. Zoosystema 27: 709-723.

Marchal P. 1892. Recherches anatomiques et physiologiques sur l'appareil excréteur des crustcés décapodes. Archives de zoologie expérimentale et générale 10: 57-275.

Martin JW, Abele LG. 1986. Phylogenetic relationships of the genus Aegla (Decapoda, Anomura, Aeglidae), with comments on anomuran phylogeny. Journal of Crustacean Biology 6: 576-616.

Martin JW, Abele LG. 1988. External morphology of the genus Aegla (Crustacea: Anomura: Aeglidae). Smithonian Contributions to Zoology 453: 1-46.

Martin JW, Davis GE. 2001. An updated classification of the Recent Crustacea. Natural History Museum of Los Angeles County, Science Series 39: 1-134.

McGaw IJ, Duff SD. 2008. Cardiovascular system of anomuran crabs, genus Lopholithodes. Journal of Morphology 269: 1295-1307.

McLaughlin PA. 1983. A review of the phylogenetic position of the Lomidae (Crustacea: Decapoda: Anomala). Journal of Crustacean Biology 3: 431-437.

McLaughlin PA, Lemaitre R. 1997. Carcinization in the Anomura - fact or fiction? I. Evidence from adult morphology. Contributions to Zoology 67: 79-123.

McLaughlin PA, Lemaitre R, Sorhannus U. 2007. Hermit crab phylogeny: A reappraisal and its "fall-out". Journal of Crustacean Biology 27: 97-115.

McLaughlin PA, Lemaitre R, Crandall KA. 2010. Annotated checklist of anomuran decapods crustaceans of the world (exclusive of the Kiwaoidea and families Chirostylidae and Galatheidae of the Galatheoidea) Part III - Aegloidea. The Raffles Bulletin of Zoology 23: 131-137.
McNamara JC, Freire CA, Torres Jr. AH, Faria SC. 2015. The conquest of fresh water by the palaemonid shrimps: an evolutionary history scripted in the osmoregulatory epithelia of the gills and antennal glands. Biological Journal of the Linnean Society 114: 673-688.

Milne Edwards H. 1837. Des décapodes anomoures. Pp. 163276 in: Milne Edwards H, ed., Histoire naturelle des crustacés, comprenant l'anatomie, la physiologie et al classification de ces animaux, tome 2. Paris: Libraire encyclopédique de Roret.

Morrison CL, Harvey AW, Lavery S, Tieu K, Huang Y, Cunningham CW. 2002. Mitochondrial gene rearrangements confirm the parallel evolution of the crab-like form. Proceedings of the Royal Society B 269: 345-350.

Ortmann A. 1892. Die Decapoden-Krebse des Strassburger Museums. IV. Theil. Die Abtheilungen Galatheidea und Paguridea. Zoologische Jahrbücher. Abtheilung für Systematik, Geographie und Biologie der Thiere 6: 241-326.

Paul HD. 1989. A neurophylogenist's view of decapod Crustacea. Bulletin of Marine Science 45: 487-504.

Paul HD. 2003. Neurobiology of the Anomura: Paguroidea, Galatheoidea: Hippoidea. Memoirs of the Museum of Victoria 60: 3-11.

Paul HD. 2004. Projection and local interneurons in the sixth abdominal ganglion of the sand crab Emerita analoga (Hippidae). The Journal of Comparative Neurology 480: 310329.

Pike RB. 1947. Galathea. LMBC Memoirs of typical British marine plants and animals 34: 1-138.

Pilgrim RLC. 1965. Some features in the morphology of Lomis hirta (Lamarck) (Crustacea: Decapoda) and a discussion of its systematic position and phylogeny. Australian Journal of Zoology 13: 545-557.

Poore GCB. 2004. Lomisidae. Pp. 240-242 in: Poore GCB, ed., Marine decapod Crustacea of Southern Australia. A guide to identification. Collingwood, Victoria: CSIRO Publishing.

Reimann A, Richter S, Scholtz G. 2011. Phylogeny of the Anomala (Crustacea, Decapoda, Reptantia) based on the ossicles of the foregut. Zoologischer Anzeiger 250: 316-342.

Richter S, Scholtz G. 1994. Morphological evidence for a hermit crab ancestry of lithodids (Crustacea, Decapoda, Anomala, Paguroidea). Zoologischer Anzeiger 233: 187-210.

Roterman CN. Copley JT, Linse KT, Tyler PA, Rogers AD. 2013. The biogeography of the yeti crabs (Kiwaidae) with notes on the phylogeny of the Chirostyloidea (Decapoda: Anomura). Proceedings of the Royal Society B 280: 1764. doi: 10.1098/rspb.2013.0718.

Schnabel KE, Ahyong ST, Maas EW. 2011. Galatheoidea are not monophyletic - Molecular and morphological phylogeny of the squat lobsters (Decapoda: Anomura) with recognition of a new superfamily. Molecular Phylogenetics and Evolution 58: 157-168.

Scholtz G. 2014. Evolution of crabs - history and deconstruction of a prime example of convergence. Contributions to Zoology 83: 87-105.

Secretan S. 1998. The sella turcica of crabs and the endophragmal system of decapods. Journal of Natural History 32: 1753-1767.

Sillar KT, Heitler WJ. 1985. The neural basis of escape swimming behavior in the squat lobster Galathea strigosa I. Absence of cord giant axons and anatomy of motor neurons 
involved in swimming. Journal of Experimental Biology 117:251-269.

Števčić Z. 1971. Main features of brachyuran evolution. Systematic Zoology 20: 331-340.

Stimpson W 1858. Pars VII. Crustacea Anomoura. Proceedings of the Academy of Natural Sciences of Philadelphia 10: 225-252.

Thurber AR, Jones WJ, Schnabel Kareen. 2011. Dancing for food in the deep sea: bacterial farming by a new species of yeti crab. Plos One 6: 11. doi: 10.1371/journal.pone.0026243

Tsang LM, Chan TY, Ahyong ST, Chu KH. 2011. Hermit to king, or hermit to all: multiple transitions to crab-like form from hermit crab ancestors. Systematic Biology 60: 616-629. Tudge CC, Scheltinga DM. 2002. Spermatozoal morphology of the freshwater anomuran Aegla longirostri Bond-Buckup \& Buckup, 1994 (Crustacea: Decapoda: Aeglidae) from South America. Proceedings of the Biological Society of Washington 115: 118-128.

Received: 25 March 2015

Revised and accepted: 15 January 2016

Published online: 16 September 2016

Editor: R. Vonk

\section{Online supplementary information}

S1. Studied specimens. Abbreviations: add, fixation additives; ZSRO\#, collection number of the Zoological Collection of the University of Rostock; m, male; f, female; inj, injection: M2, Mercox 2 resin; PU4, PU4 resin; fix, fixation: GA, glutaraldehyde; CT, micro computer tomography; TEF, Tetric EvoFlow $\mathbb{C}$; J, iodine; n.a., not determined.

S2. Ventral view of female Lomis hirta. Asterisk indicates $6^{\text {th }}$ pleonal segment. Abbreviations: p1-p2, pereiopods; t, telson.

S3. Anterior ceca (arrows) in Kiwa puravida (A, B), Lomis hirta (C, D) and Aegla cholchol (E, F). Surface renderings. Arrowhead indicates posterior cecum.

S4. Antennal gland and antennal bladder of A. cholchol (A-B), L. hirta (C-D) and K. puravida (E-F). A, C, E, dorsal view. B, D, F, frontal view. Abbreviations: a2a, antennal artery; ag, antennal gland; aga, antennal gland artery; Ala, anterior lateral artery; ao, anterior aorta; bl, antennal bladder; fa, fringe artery, ra, rostral artery.

S5. Antennal bladder in Aegla cholchol (volume renderings). A. Dorsal view. Arrows indicate loops. B. Frontal view. Red line indicates looped tube. Abbreviations: ag, antennal gland; bl, antennal bladder.

S6. Ventral vessel system and endophragmal skeleton (volume and surface renderings). A. Kiwa puravida. Cephalothorax virtually opened. Yellow arrow points to transverse thoracic bridge. B. K. puravida. Cephalothorax virtually opened. C. Aegla cholchol. Cephalothorax virtually opened. Dashed yellow line indicates transverse thoracic bridge. D. Lomis hirta. Ventral view. Plastron and carapace virtually removed.

S7. Lateral view of integumental and endophragmal elements of cephalothorax and pleon and associated muscles. A. Kiwa puravida. B. Aegla cholchol. Note the twofold articulation (circles) and greater length of the endophragmal lever in K. puravida. Circles indicate articulation of the endophragmal lever. Squares indicate joint with the first pleonal sternites. Arrows indicate dorsal extrusion of the seventh thoracic pleurites. Asterisks indicate broad apodemes of the endophragmal levers. Abbreviations: dpm, dorsal pleonal muscles; lpm, lateral pleonal muscles; lv, endophragmal levers; lvm, lever adductor muscles; m-a, m-b, m-c, dorso-lateral thoracic muscles; pl1-3, pleonal tergites; pst1, first pleonal sternites; tpl5-7, thoracic pleurites.

S8. Lateral view of thoracic and pleonal muscles. A. Kiwa puravida. B. Aegla cholchol. C. Lomis hirta. Circles indicate articulations of the endophragmal levers. Squares indicate joint with the first pleonal sternites. Abbreviations: dpm1-5, dorsal pleonal muscles; dtm8, dorsal thoracic muscles; lpm2-5, lateral pleonal muscles; 1v, endophragmal levers; lvm, lever adductor muscles; m-a, m-b, m-c, dorso-lateral thoracic muscles; pfm, thoracopleonal flexor muscles; pxm, thoracopleonal extensor muscles; vpm2-5, ventral pleonal muscles. 
Online supplementary information - cont.

S9. Dorsal view of thoracic and pleonal muscles. A. Kiwa puravida. B. Aegla cholchol. C. Lomis hirta. Asterisks indicate eighth dorsal thoracic muscles (dtm8). Arrows in B (A.cholchol) indicate vestigial muscles corresponding to the m-c-muscles in K. puravida and L. hirta. Abbreviations: dpm1-4, dorsal pleonal muscles; dtm8, dorsal thoracic muscles; lpm2-4, lateral pleonal muscles; lv, endophragmal levers; lvm, lever adductor muscles; m-a, m-b, m-c, dorso-lateral thoracic muscles; pxm, thoracopleonal extensor muscles; vpm2, second ventral pleonal muscles.

S10. Heart structures. A-C. Position of the heart within the body in A. Aegla cholchol, B. Kiwa puravida and C. Lomis hirta (surface renderings). White line indicates border between cephalothorax and pleon. Note the significant differences in distances between the heart and the posterior margin of the cephalothorax. D. Lateral view of the heart in A. cholchol (surface rendering). Asterisks indicate ostia. Arrow indicates roots of posterior aorta and descending artery. E. Frontal view of the heart in L. hirta (surface rendering). Asterisks indicate anterior dorsal ostia. F-G. Virtual horizontal section through the heart in L. hirta showing the ventral intrinsic muscle strands (volume (F) and surface (G) rendering). Arrows indicate a distinct pair of strands. Abbreviations: ala, anterior lateral arteries; ao, anterior aorta; h, heart; ila, inferior lateral arteries; myc, myocardial muscle strands; pl1, first pleonal segment.

S11. Dorsolateral view of the cephalothorax of Lomis hirta, virtually opened (volume rendering). gi, gills; h, heart; Hp, hepatopancreas; lps, lateral portion of the pericardial septum; m-a, dorsal thoracic muscles a; ov, ovaries; pm, posterior gastric muscles; tm, vertical thoracic muscles; tpl, thoracic pleurites.

S12. Kiwa puravida. Arrows indicate paired muscle strands flanking the anterior aorta (volume and surface renderings). Abbreviations: am, anterior gastric muscles; ao, anterior aorta; cp, carapace; eso, esophagus; mda, mandible artery; stc, stomach.

S13. Mouthpart arteries. Surface renderings (A-F) and volume rendering (F). A-C. Aegla cholchol. Frontal view. Note the variable, partly asymmetrical pattern of the arteries. Arrowhead indicates major artery which emanates asymmetrically and supplies the right mandible and parts of the esophagus. Asterisks indicate small ascending esophageal arteries. D. Kiwa puravida. Frontal view. E. K. puravida. Posterodorsal view showing the endophragmal scaffold separating the arteries. F. Lomis hirta. Frontal view. Abbreviations: es, endosternites; eso, esophagus; md, mandibular artery; mx1-mx2, maxillar arteries; mxp1-mxp3, maxillipedal arteries; scg, scaphognatite artery. 